\title{
Las políticas urbanísticas municipales en España: 40 años de ayuntamientos democráticos (1979-2019)
}

\author{
Municipal planning policies in Spain: \\ 40 years of democratic city councils (1979-2019)
}

\author{
Carme Bellet Sanfeliu \\ carme.bellet@udl.cat \\ Departamento de Geografía y Sociología \\ Universitat de Lleida (España)
}

\section{Resumen}

En los últimos 40 años, las ciudades españolas han cambiado mucho dentro de un marco más general de profunda transformación política, social y económica del país. A través fundamentalmente del análisis bibliográfico y documental el trabajo trata, en primer lugar, de contextualizar y caracterizar la evolución de las políticas urbanísticas desplegadas desde los primeros ayuntamientos democráticos hasta la actualidad e identificar el modelo de ciudad en el que éstas se han ido basando a la vez que construyendo (física y simbólicamente). Para ello, se establecen tres períodos de análisis temporal: 1979-1991; 1992-2007 y 2008-2019, cuya delimitación se realiza teniendo en cuenta, también, la evolución de la dinámica inmobiliaria y las fechas de celebración de las elecciones municipales. Finalmente, se caracteriza el urbanismo del último de los períodos tras la crisis financiera e inmobiliaria (2008-2019), durante el cual, y especialmente tras las elecciones municipales en 2015, irrumpieron en algunos gobiernos locales, partidos y coaliciones que surgieron de los movimientos del 15 M de 2011. 
Palabras clave: urbanismo; planificación urbana; ciudades españolas; urbanismo neoliberal; políticas urbanas.

\begin{abstract}
Over the past 40 years, Spanish cities have changed considerably. This has occurred within a wider framework of deep-seated political, social and economic transformation. This work is mainly based on bibliographical analysis and a review of relevant territorial planning documentation. Firstly, it aims to contextualise and characterise the evolution of the urban policies that have been applied from the arrival of the first democratically-elected city councils through to the present day and to identify the city model in which these changes have been thought up and (physically and symbolically) constructed. To do this, we established three periods for our analysis: 1979-1991, 1992-2007, and 2008-2019. This division was made while also taking into account the evolution and dynamics of the property market and the dates on which municipal elections were held. Secondly, it tries to characterise the nature of urbanism during the last of these periods, after the financial and property crisis (2008-2019). During this period, and particularly after the 2015 municipal, the parties and coalitions that emerged from the 15th May 2011 movements, managed to enter some local government bodies.
\end{abstract}

Key words: urbanism; urban planning; Spanish cities; neoliberal urbanism; urban policies.

\title{
1 Introducción
}

Aunque no existe una única definición de aquello que entendemos por políticas urbanas, y que necesariamente debemos utilizar en plural, podemos convenir que son medidas y acciones, gestionadas y desarrolladas por un gobierno local, cuyo objetivo es incidir en aquello que en cada momento se entiende como problemático o necesario en la ciudad.

Diversos estudios han mostrado la gran variabilidad de las políticas urbanas que cambian en función del contexto geográfico, marco institucional, situación política y social y, características de los actores locales (Iglesias et al., 2011). De hecho, son las ciudades las que reflejan de manera más intensa los cambios económicos, políticos y sociales que se han producido en las últimas décadas.

De entre los muchos e interrelacionados factores de cambio que nos ayudan a interpretar la evolución más o menos reciente de las políticas urbanas destacaríamos los relacionados con la globalización contemporánea, que han convertido a las ciudades en actores económicos 
políticos y culturales de primer orden. Ello ha implicado un reposicionamiento del papel del Estado y, en paralelo, de los gobiernos locales (Martí-Costa \& Tomàs, 2016). ${ }^{1}$ Ese reposicionamiento de lo local ha conllevado la redefinición del papel de la autoridad municipal que pasa a desplegar estrategias de desarrollo orientadas a definir el perfil competitivo de las ciudades y su promoción, aspecto éste muy pronunciado en un contexto de políticas neoliberales generalizadas desde la década de los 80. En este marco las políticas económicas y urbanísticas, a través de diferentes modalidades de planificación e intervención (como los planes estratégicos, el marketing urbano y los grandes proyectos urbanos), se irán convirtiendo en las grandes protagonistas de las políticas públicas urbanas.

El artículo se despliega a partir de una serie de planteamientos básicos que podemos concretar en los siguientes:

1. Las políticas urbanísticas desplegadas desde las instituciones públicas locales (con su acción u omisión) han jugado -y juegan - un rol protagónico en las dinámicas y características de la urbanización, así como en los modelos y visiones sobre lo urbano y la ciudad que se producen e imponen en cada momento (Capel, 2013a; Burriel, 2008). Como apunta Cochrane (traducción de la autora): "La política urbana (y la urbanística por extensión - añadido por la autora), es tanto, una expresión de aquello que se entiende que en cada momento es lo urbano, lo que hace que las ciudades sean lo que son, a la vez que contribuye a dar forma a esas comprensiones" (Cochrane, 2007, p. 13).

2. El planeamiento y las políticas urbanísticas que se despliegan a escala local responden a la combinación de las tradiciones y enfoques (visiones sobre lo urbano y la ciudad) y de los contextos sociopolíticos y económicos existentes en los diferentes momentos (Díez \& Monclús, 2017; López de Lucio, 1993a). Aquí queremos puntualizar que pese a las diferencias de las políticas urbanísticas presentes en las diferentes Comunidades Autónomas tras el progresivo traspaso de competencias en urbanismo y ordenación del territorio durante los años 80 , existen líneas comunes que permiten establecer un marco explicativo general del urbanismo municipal desplegado en el país desde la llegada de los primeros ayuntamientos democráticos en 1979 (Calderón \& García Cuesta, 2017). Aunque, los estatutos de autonomía las presenten como propias, el Estado mantiene la competencia exclusiva en una serie de materias (art. 149.1 de la Constitución Española)

1 Ante la permanencia del Estado como actor político, aún relevante, y la simultaneidad de lo local y lo global, los analistas han elaborado la idea del gobierno multinivel y la idea del "reescalamiento" (Brenner, 2004). 
que tienen una gran incidencia en el urbanismo y la ordenación del territorio, ${ }^{2}$ como son: la regulación del contenido de la propiedad urbana o la programación y ejecución de las llamadas infraestructuras de interés general.

3. El neoliberalismo y la financiarización de las ciudades explican que el gobierno de las ciudades sea concebido, cada vez más, como una función puramente gerencial, privándolo de la dimensión política que le es propia (Harvey, 2013). Las nuevas formas de gobierno de la ciudad, en pro de su gobernabilidad, estarían basadas en la inclusión de actores del mercado privado, grupos de la sociedad civil y partes del aparato estatal tradicional, siendo en general adjetivadas como "participativas". Sin embargo, en buena parte de los casos los procesos participativos no dejan de ser "autocráticos", puesto que los objetivos o la imagen final no pueden cuestionarse al estar, en muchos de los procesos de participación, previamente definidos (Swyngedouw, 2005; Sennet, 2018). ${ }^{3}$ Además, como ya destacó Jordi Borja "si bien la urbanización se expresa en el ámbito local, el marco político y económico que la hace posible, es estatal y global (...) El motor de este proceso han sido las entidades financieras mediante créditos e hipotecas justificadas por la expectativa de altos beneficios especulativos" (Borja, 2011, p. 84).

El artículo trata, en primer lugar, de contextualizar y caracterizar la evolución de las políticas urbanísticas, en especial el planeamiento, desde los primeros ayuntamientos democráticos hasta la actualidad y presentar el cambio de modelo de ciudad en el que éstos se basan a lo largo de los diferentes períodos. Así, se interroga sobre: 1) el origen y las características de las políticas urbanísticas actuales; 2) cómo estas y el modelo urbano han ido cambiando desde 1979; 3) cómo su ejecución ha comportado la transformación de las ciudades y de las áreas urbanas que estas articulan. Para ello se establecen tres períodos diferentes de estudio (1979-1991; 19922007 y 2008-2019), que se delimitan en función de las características del urbanismo desplegado a escala municipal, las fechas de celebración de las elecciones municipales y la evolución de la dinámica inmobiliaria, tal y como se muestra en la Figura 1.

2 Además, y como señala Onofre Rullán: "ante una eventual discrepancia entre los proyectos del Estado y los de las CCAA los tribunales vienen reconociendo la llamada "cláusula de prevalencia" (Art. 149.3 de la CE) a favor del primero "(Rullán, 2016, p. 1270)

3 Siguiendo a Swyngedouw, la post-política se basa tanto en tratar de incluir a todos en un orden pluralista de consenso como en excluir radicalmente a quienes se postulan fuera del consenso. Para ello, las contradicciones políticas se reducen a problemas de política que deben ser manejados por expertos y legitimados a través de procesos participativos, en los cuales, el alcance de los posibles resultados es definido de antemano (Swyngedouw, 2005, p. 1993) 
Las políticas públicas de finales de los setenta y los ochenta se enfrentaban, por un lado, a unos problemas y situaciones que eran propias todavía de una sociedad industrial clásica (Subirats, 2016) y, por otro, a unas ciudades que arrastraban fuertes déficits urbanos heredados de las décadas de la dictadura franquista (López de Lucio, 1993a; Ferrer \& Sabaté, 1999).

Más adelante, y de forma clara en los años noventa, las políticas urbanas, y con ellas las urbanísticas, cambiarían con la aplicación de políticas de liberalización económica, el pleno despliegue de las estrategias de competitividad urbana y el city marketing mediante las cuales, las autoridades de un número creciente de ciudades, buscarían explícitamente atraer recursos y capitales externos. Con ello, aumentó la mercantilización de las ciudades a través del fomento de las inversiones inmobiliarias privadas (y privatización de la gestión de los servicios urbanos) en el marco de la creciente movilidad del capital producido por la globalización financiera (Méndez, 2018).

El artículo de detiene en el último de los períodos (2008-2019), para reflexionar sobre la características y composición de las nuevas agendas urbanas que algunos gobiernos locales fueron desplegando a partir de la crisis y de forma especial a partir de las elecciones locales de 2015 (Díaz Orueta et al., 2018). Las nuevas políticas y acciones desplegadas, especialmente por los llamados ayuntamientos del cambio y municipalistas, trataron de innovar en un contexto de recursos públicos limitados, gobiernos muy diversos y políticamente débiles y demanda de mayor participación ciudadana por parte una sociedad cada vez más compleja y desigual (Subirats, 2016; Nel.lo, 2015). Así las nuevas acciones y políticas, algunas innovadoras y experimentales, incidieron en un cambio importante en el tipo de intervenciones realizadas. Las metodologías y las formas de gobernanza tradicionales asumieron lógicas alternativas y participativas que, sin embargo, no cuestionaban el funcionamiento del mercado del suelo dentro del sistema capitalista ni la lógica del urbanismo neoliberal (Sennet, 2018; Swyngedouw, 2018).

La revisión bibliográfica y documental de documentos de planeamiento, así como la información sobre los principales planes y proyectos reseñados en monografías diversas y las principales revistas de urbanismo y de estudios urbanos del país, son las principales fuentes de trabajo. ${ }^{4}$

4 Se ha trabajado con el fondo de las siguientes revistas que se citan en orden alfabético: Anales de Geografía, Biblio3W, Boletín de la Asociación de Geógrafos Españoles, Ciudad y Territorio-Estudios Territoriales, revista Ciudades, Cuadernos de Geografía, Cuadernos Geográficos, Cuadernos de Investigación Geográfica, Cuadernos de investigación urbanística del Departamento de Urbanística y Ordenación del Territorio de la Escuela Técnica Superior de Arquitectura de Madrid, Documents d'Anàlisi Geogràfica, Ería-revista cuatrimestral 
Para el estudio de las dinámicas de urbanización e inmobiliaria, se utilizan datos de la construcción de viviendas (viviendas terminadas) del Ministerio de Fomento (1975-2018), así como datos procedentes de la explotación del proyecto Corine Land Cover sobre los procesos de artificialización del suelo para los años: 1987, 2000, 2011 y 2018. Además, se ha recurrido a los datos que, sobre planeamiento municipal, potenciales de vivienda y suelo y edificabilidad de los mismos, se presentan en el Sistema de Información sobre Ocupación del Suelo de España (SIOSE) con información procedente del Ministerio de Fomento en la versión disponible en línea de 2018.

\section{Planeamiento municipal, urbanismo y dinámica inmobiliaria (1979-2018)}

Diversos estudios han ido mostrando la fuerte vinculación del crecimiento económico y expansión del sector inmobiliario desde mediados de siglo XX en España (Rodríguez López, 2006), para acabar configurando un modelo urbano expansivo, especulativo e insostenible (Naredo, 2010). Así, los diferentes períodos de crecimiento económico en el país se han basado en expansiones de la actividad inmobiliaria con la producción, más o menos intensa de: infraestructuras, suelo urbano e inmuebles. Estas expansiones han sido ya secuenciadas en otros estudios en tres momentos de expansión inmobiliaria (Rodríguez López, 2006; Górgolas, 2017) y que se representan en la Figura 1. El primero de los períodos sería el franquista, que se produce entre 1963-1973; el segundo, el de la nueva democracia, entre los años 1985-1992, y, el último, el más reciente, de la llamada década prodigiosa del urbanismo español, entre 1997-2007. Estas expansiones de la actividad inmobiliaria han ido dejando su particular huella espacial que fue avalada en cada momento por un tipo de planeamiento y por unas políticas urbanísticas específicas.

El planeamiento urbano (y el territorial) expresan las condiciones socioeconómicas y culturales en que estas se conciben y despliegan y, por ello, sus fundamentos, sus orientaciones estratégicas y directrices se adaptan a estas (Calderón \& García Cuesta, 2017). Pero, además, en el marco del especial modelo de capitalismo inmobiliario español, imperante desde mediados de siglo XX, el planeamiento y la gestión urbanística desde lo público se han ido convirtiendo en el instrumento básico para catalizar las expectativas de crecimiento económico, basadas, casi de forma exclusiva, en el consumo de territorio (Górgolas, 2017). Ello básicamente se ha ido

de Geografía, Estudios Geográficos, Geometría, Investigaciones Geográficas, Planur-E, Quaderns d'Arquitectura y Urbanisme (editada hasta 2010), Revista de Urbanismo - COAM, Scripta Nova, Urbs, Urban-E. 
produciendo cuando la expectativa de la plusvalía generada por la urbanización ha resultado superior a las de cualquier otra actividad. Así, la ciudad, y la producción de lo urbano "se convierte en un mecanismo de absorción de excedentes de capital e integrarse en el circuito de acumulación" (Lois et al., 2016, p. 7). De esta forma la legislación y la actividad urbanística parecen haber ido alimentado la dinámica inmobiliaria y la producción de lo urbano, convirtiendo la ciudad y el territorio en el propio negocio (Calderón \& García Cuesta, 2018)

Figura 1. Evolución de la construcción de viviendas terminadas en España (1975-2017) y fechas de celebración de elecciones municipales

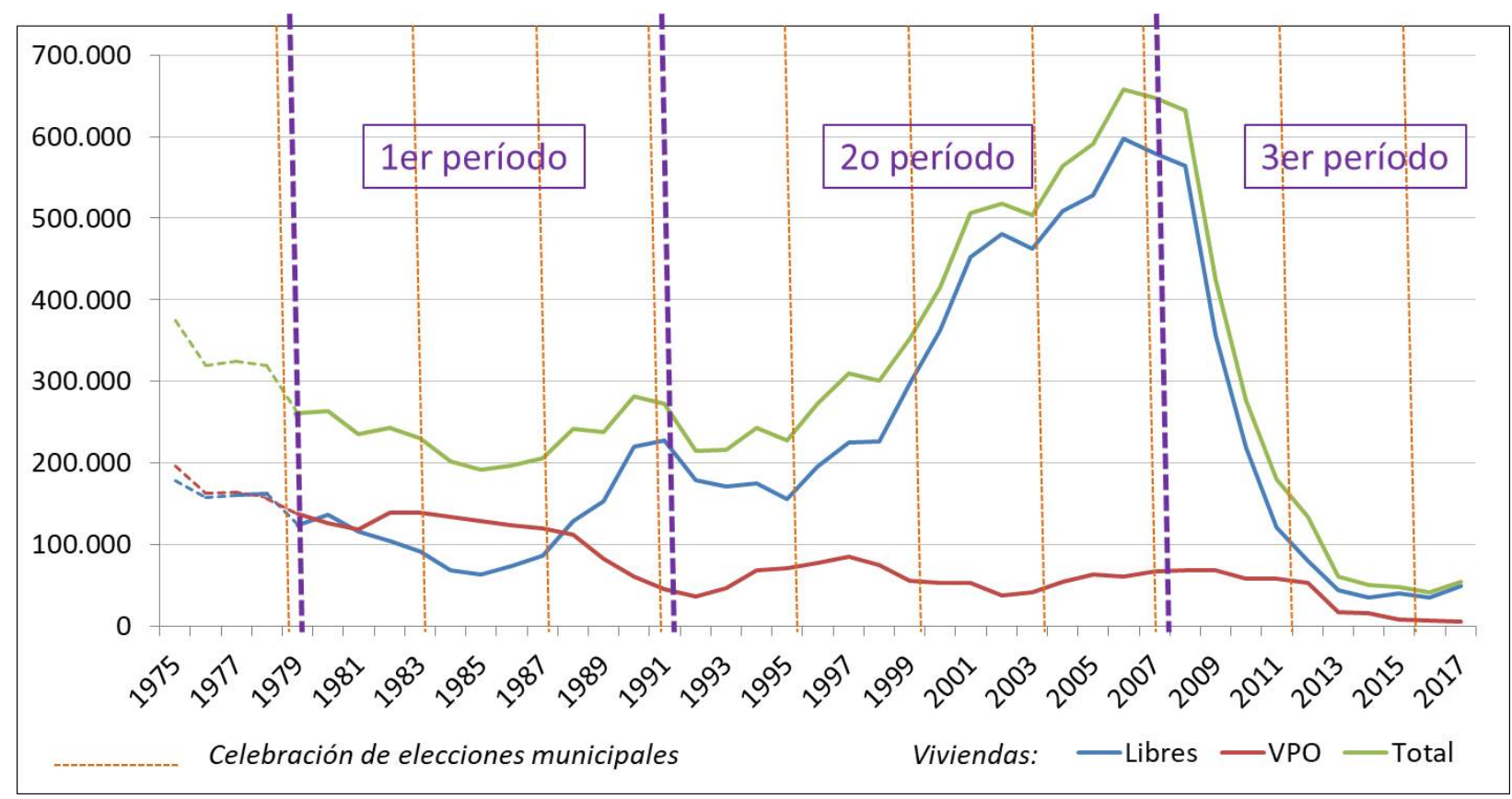

Fuente: Ministerio de Obras Públicas y Ministerio de Fomento, Ministerio del Interior

El primero de los períodos (1979-1991) arranca en el medio de la fuerte crisis que se gesta en las economías de occidente entre 1975 hasta 1985. A ello, en España, se unió la incertidumbre asociada al fin de la dictadura, en un contexto de una economía emergente pero aún con fundamentos débiles. Con la integración del país en la Comunidad Económica Europea se refuerza la internacionalización de la economía y la centralidad que iría adquiriendo la economía financiera, convirtiéndose en destino de la inversión internacional que, en España, se dirigía principalmente a los mercados financieros e inmobiliarios (López \& Rodríguez, 2010). Todo ello concluye en una burbuja especulativa causada por el "efecto riqueza" creado en las familias ante el aparente incremento de valor de sus activos (Naredo, 1996). La recuperación económica de mediados de los años 80 (1985-1992), período durante el cual el PIB crecía a un ritmo 
anual del $6 \%$, estuvo alimentado también por la dinamización turístico-inmobiliaria que fue ya instaurada durante la dictadura en la década de los años 1960.

De los trabajos de algunos autores puede concluirse que, en ese período de expansión económica, fuertemente basado en las rentas financieras e inmobiliarias, se fueron retroalimentando dos procesos espaciales que se produjeron en paralelo (Górgolas, 2017; Rullán, 2012):

- La inversión en infraestructuras de transporte, financiadas por los fondos estructurales, se convirtió en la espoleta del mercado inmobiliario. En España ello representa un importante negocio para el sector ya que se produce una coincidencia entre los grupos empresariales explotadores de infraestructuras y los que se dedican a la producción inmobiliaria. Además, la inversión en infraestructuras de transporte contribuye a eliminar la fricción de la distancia, que como apuntan Isidro López y Emmanuel Rodríguez "es una condición necesaria para la escalabilidad (y seguridad) de los mercados inmobiliarios" (López \& Rodríguez, 2010, p. 316).

- La expansión del mercado inmobiliario gracias al fácil acceso a la financiación derivado de la desregulación del mercado. El Decreto Boyer de 1985, con medidas económicas, fiscales y crediticias, activó el mercado inmobiliario incentivando la demanda residencial y las subvenciones fiscales que contaban con el apoyo de un sistema de financiación. Sin embargo, en un contexto de escaso crecimiento demográfico y bajo movimiento migratorio, el efecto de la burbuja afectó fundamentalmente a los precios, no tanto al volumen de lo construido o a una excesiva demanda de suelo, como se aprecia en el gráfico 1 (Naredo, 1996). Dicha situación pues, no entraría en conflicto con el modelo urbano propuesto por el planeamiento aprobado durante la década de los 80, cuyos objetivos se dirigían principalmente, y como veremos con mayor detalle en el siguiente apartado, a la reforma y a la mejora de la ciudad más o menos consolidada y no tanto al crecimiento. Así, los modelos urbanos propuestos por los planes del llamado "urbanismo urbano" se fueron adaptando progresivamente a la coyuntura del momento, a través del mecanismo de las modificaciones puntuales o parciales. Sin embargo, desde los sectores financiero e inmobiliario se trasladaba la responsabilidad del encarecimiento del precio de la vivienda a la escasez de suelo que, según estos, era consecuencia directa de la contención de desarrollo de suelo del "urbanismo urbano" y se presentaba como solución la desregulación (Górgolas, 2017). 
El ciclo alcista iniciado en 1985 terminó por problemas financieros tras los festejos de 1992 (Rodríguez \& López, 2006). Pero, los fundamentos de la política económica y de suelo, basados en la desregulación del mercado, quedaron latentes durante la crisis posterior y se convirtieron en hegemónicos, entre 1997 y 2007 durante el último boom inmobiliario. La llegada del euro, los bajos tipos de interés, y un marco político propicio, provocaron una huida hacia delante de la economía española desencadenando un nuevo ciclo alcista mucho más especulativo e intenso que el anterior (Naredo, 2010; Buriel, 2014).

En este nuevo contexto, y como veremos, el planeamiento urbano y el territorial venían a poner límites y resultaban restrictivos, por lo que fueron sometidos por el proyecto, la planificación estratégica y el marketing urbano (Fernández Durán, 1993). Estos nuevos instrumentos eran entendidos por el mercado inmobiliario como una oportunidad para erosionar las regulaciones del planeamiento a la búsqueda de la liberalización del suelo. Sin modelo urbano y territorial de referencia era más fácil vehicular las demandas individualizadas de los agentes privados y, para ello, la escala concreta del proyecto representaba el soporte instrumental idóneo. Junto a ello, la liberalización del mercado del suelo y la situación financiera y política propicia actuaron de espoleta de un proceso de urbanización y construcción que ya se ha venido caracterizando como intensivo, extensivo y privativo (Calderón, 2004; Bellet, 2007).

\section{La evolución de las políticas urbanísticas municipales (1979-2019)}

\subsection{Primer período (1979-1991). El urbanismo urbano, reformista y social}

Tras la dictadura franquista, y con el cambio político que reinstauraba la democracia, llegaron los procesos de descentralización. Estos comportaron que los ayuntamientos (y otras entidades locales y autonómicas) fueran asumiendo competencias específicas sobre planificación espacial. Con ello, irrumpieron nuevas formas de hacer ciudad vinculadas a la reivindicación de las características diferenciales de los territorios.

Los nuevos ayuntamientos democráticos, recién constituidos, emprendieron la construcción de una agenda política municipal en la que el urbanismo ocuparía, en este primer período, un papel protagonista. Pero ello, y a diferencia de lo que sucedía en el centro y norte de Europa, donde eso ya se hacía a través del desarrollo de proyectos urbanos, en España se siguió la tendenza italiana de hacerlo a través del Plan (Sainz, 2006; Hall, 1996). El urbanismo, y especialmente la planificación urbana, se consolidaron como el gran proyecto político de los 
primeros ayuntamientos democráticos, la bandera de la nueva política municipal que se erigió inspirada en un cierto "keynesianismo espacial" (Subirats, 2016).

Así, y primero, los nuevos consistorios empezaron revisando el planeamiento municipal general, en un sentido que iba más allá de la mera adaptación de la nueva Ley del Suelo de 1975. Con la revisión, se introdujeron nuevas visiones, acordes a los momentos del cambio, que priorizaron: la reestructuración, la reforma y la mejora de la ciudad ya existente. De hecho, los años ochenta han sido considerados la "era dorada" del planeamiento urbano español no solo por la cantidad de nuevos planes, sino y sobre todo, por su calidad (MOPU, 1990).

Las ciudades, desde diferentes ángulos, se miraban hacia dentro con una filosofía general basada en los valores de un urbanismo que podríamos calificar de urbano, reformista y social. ${ }^{5}$ En primer lugar, se califica de urbano porque este tipo de urbanismo centraba su atención en la mejora de la estructura y tejido urbano ya consolidado y en la corrección de los déficits urbanísticos heredados del desarrollismo franquista (infraestructuras, servicios y equipamientos) especialmente en los barrios periféricos más desfavorecidos (Solà-Morales \& Parcerisa, 1987). Así, se elaboraron planes que, bajo la influencia italiana, prestaban mucha atención a la estructura general, a la forma y a la relación entre el tejido construido y el espacio público (Bellet, 1995). En segundo lugar, se imponía la reforma y la transformación urbana frente al crecimiento (Gaja, 2008). Todo ello, dando un notable protagonismo al interés colectivo y, algunas veces, a los procesos de colaboración de los nuevos y ampliados equipos de técnicos municipales con las todavía entonces dinámicas asociaciones de vecinos. ${ }^{6}$

Muestra de ello son los Planes Generales de Ordenación Urbana de Málaga (1983), Salamanca (1984) Valladolid (1984), A Coruña (1985) o Gijón (1985). A título de ejemplo el Plan General de Valladolid, dirigido por Bernardo Ynzenga Acha, un plan que reconoce lo existente y concibe los moderados crecimientos rellenado vacíos entre tejidos heredados y tratando de recomponer el conjunto de la estructura y forma urbana a partir del viario y el espacio público (Sainz 2006; Fernández Maroto, 2015).

5 Antonio Font califica de "remediales" a los Planes aprobados en estos primeros años de los 80: "su preocupación primordial por la resolución de las carencias de la ciudad hace que denominemos los planes como remediales, correctores de los déficits en los elementos de carácter público o colectivo recomponiendo, así, la ordenación urbana" (Font, 2000, p. 67).

6 "...las alianzas forjadas entre activistas, intelectuales y técnicos durante los años finales del franquismo en muchas ciudades fueron decisivas para poner en marcha planes concretos de infraestructura y servicios que el franquismo no había realizado..." (Subirats, 2016, pp. 30). 
Figura 2. Modelo espacial del Plan General de Valladolid de 1984

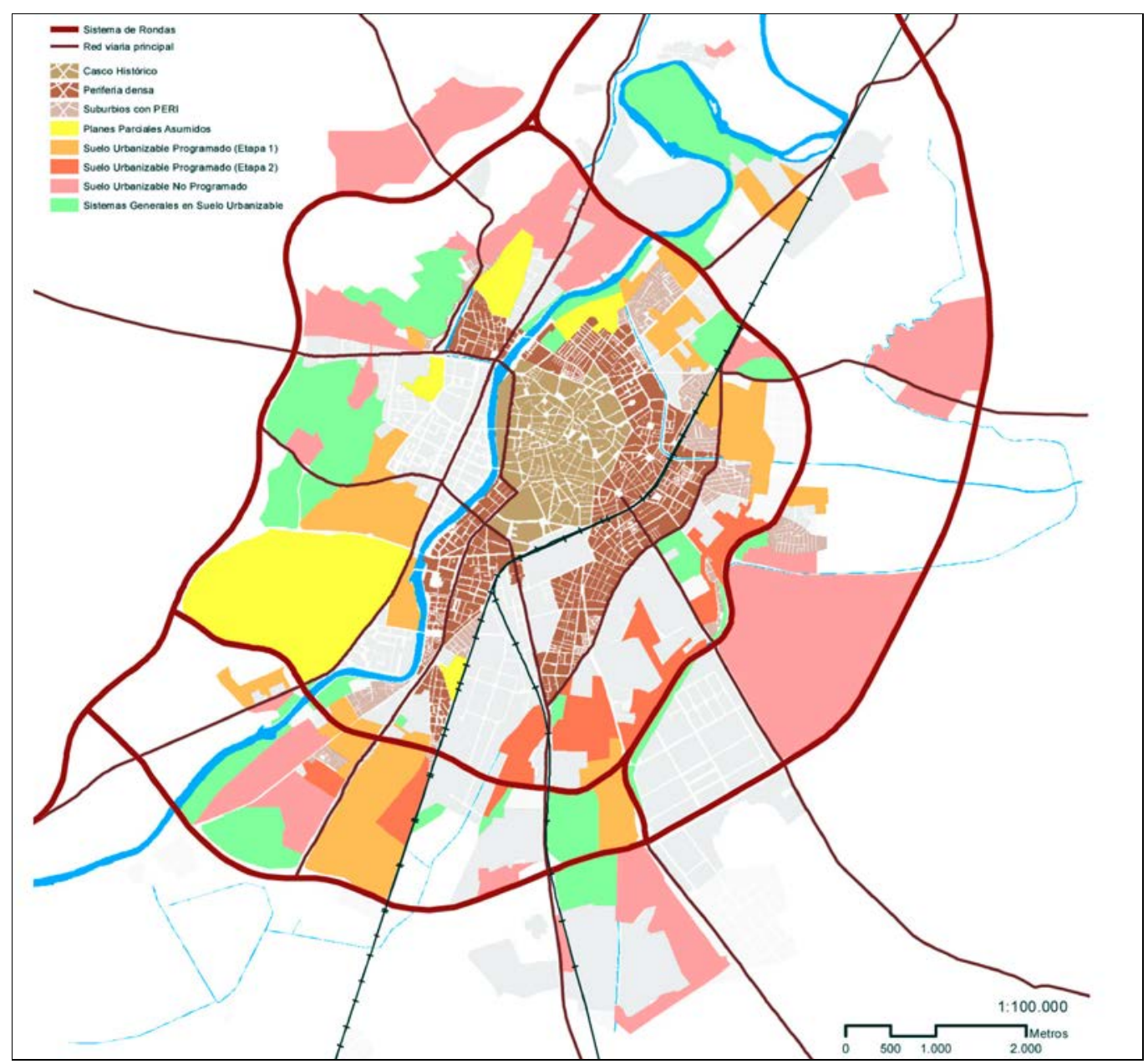

Fuente: Fernández-Maroto (2015, p. 261)

Son destacables también en ese período los cerca de 200 planes impulsados por la Generalitat de Catalunya a principios de los años 80 , recién adquiridas las competencias en urbanismo, muchos de ellos redactados por miembros relacionados con el Laboratori d'Urbanisme de la Escola Tècnica Superior d'Arquitectura de la Universitat Politècnica de Barcelona. Entre ellos, destacan los destinados a ciudades medias como los de Vilafranca del Penedès (1982), Tarragona (1984), Girona (1986), u otros como los de Manresa (1981) o Lleida (1979), entre otros (Ferrer \& Sabaté, 1999). Planes que en conjunto pueden calificarse de contenidos en cuanto a las previsiones de crecimiento, centrándose en la reestructuración del conjunto, la compactación, y la mejora de los centros y barrios desestructurados de la periferia. Se pretendía también regular los usos y las intensidades de la edificación, a través de normativas y 
ordenanzas más concisas, tanto para la ciudad existente como para los nuevos crecimientos (Font, 2000). ${ }^{7}$

De hecho, los barrios más desfavorecidos e infradotados de la primera periferia urbana fueron objeto de intervención preferente, adquiriendo en los primeros años de la reinstaurada democracia el carácter de sujeto político, en buena parte por el impulso de las movilizaciones vecinales durante el tardofranquismo. Ello contribuyó al establecimiento de una agenda urbana con un notable carácter social durante los primeros años (Rivas et al., 2017).

Al respecto uno de los ejemplos más emblemáticos de las actuaciones desarrolladas en las periferias urbanas del momento fueron los Programas de Acción Inmediata (PAI) y la remodelación de barrios en Madrid (1978-1979). Los PAl fueron promovidos, entre 1978 y 1979, por la COPLACO (Comisión de Planeamiento y Coordinación del Área Metropolitana de Madrid) en el marco de la Revisión del Plan General del Área Metropolitana y tenían como objetivo principal la remodelación y el equipamiento de las vulnerables periferias. Pero quizás lo más característico de los PAI fuera, primero, que partían de visiones integrales y, segundo, el método utilizado ya que las estrategias y las actuaciones se definían y consensuaban a través de amplios procesos de participación vecinal (Moya, 1981).

Respecto al planeamiento derivado fueron también importantes, en este primer período, los planes especiales de reforma, protección y mejora de conjuntos y centros históricos de muchas ciudades españolas, que se acompañaron de la financiación procedente de la experiencia de las Áreas de Rehabilitación Integrada (ARI) impulsadas desde el MOPU. A título de ejemplo, los elogiados en revistas especializadas españolas: el Plan especial del centro histórico de Gijón (1987), el Plan del Centro Histórico de Lleida (1985), el del Centro Histórico de Tarragona (1984), el Plan de Arquitectura y de Rehabilitación de Alcoy (1984) o el paradigmático de Vitoria-Gasteiz aprobado en 1988. En 1982 se inician los trabajos de redacción del Plan Especial de Rehabilitación Integrada de Vitoria-Gasteiz tras el progresivo despoblamiento del centro, las deficientes condiciones de habitabilidad de buena parte de las viviendas, el precario estado de las infraestructuras y equipamientos y la pérdida de servicios y actividades económicas del otrora espacio central. El Plan pretende revertir la situación articulando sus estrategias con instrumentos

7 Interesante es la crítica que realiza Antonio Font a los planes "morfologistas" de este primer periodo: "la intención de la operatividad se traducía en la necesidad de fijar criterios y prioridades de intervención, y en la tendencia a comprometer, a veces en demasía, soluciones concretas de forma urbana" (Font, 2000, p. 71). 
y estructuras de gestión locales e instrumentos que inyectan financiación. ${ }^{8}$ De hecho, entre 1983 y 1990, se procede a la renovación completa de las infraestructuras y pavimentación general del viario, se rehabilitan cerca de 2000 viviendas y se promueven un número importante de equipamientos y dotaciones en el área de rehabilitación integral (Rodríguez, 2011).

Figura 3. Las propuestas del Programa de Acciones Inmediatas (PAI) de la COPLACO para Colmenar Viejo (Madrid)

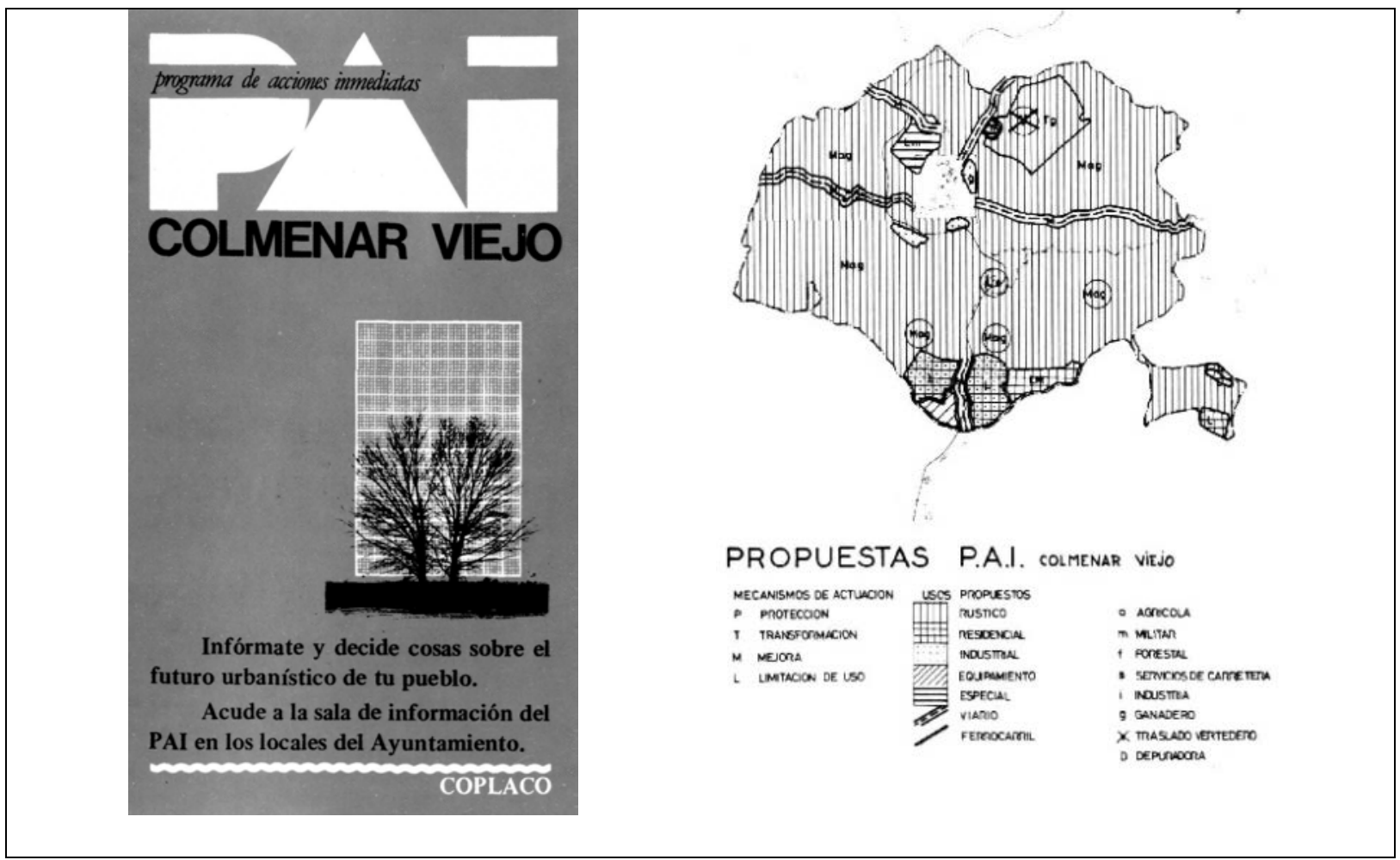

Fuente: Reproducción de Moya (1981, p. 38 \& 43)

Con el cambio de década, sin embargo, y como apunta Sainz: "las intervenciones en los centros históricos comenzarían a perder en tensión crítica lo que ganaron en eficacia mediática, dentro del proceso contemporáneo de sustitución de la realidad por sus imágenes" (Sainz, 2006, p. 167) y dentro del proceso general de substitución de planes por grandes proyectos urbanos.

En unos planes tan centrados en completar la ciudad y en unas intervenciones principalmente dirigidas a la modificación de lo existente, las cuestiones territoriales, los procesos de desconcentración de la población y las actividades en el territorio, tuvieron, cuando menos, un

8 Entre ellas la creación en 1977 del Departamento de Centro Histórico dentro de la estructura municipal, la reconversión del Departamento en Sociedad Anónima en 1982, el primer decreto de ayudas a la rehabilitación del Gobierno Vasco en1983/88 y ya en 1994 la transformación del Departamento del Centro Histórico en la Agencia de Renovación Urbana y Vivienda S.A. El Plan Especial se revisó a principios de los años 2000 siendo aprobado definitivamente el nuevo PERI en 2006. 
tratamiento insuficiente (López de Lucio, 1993b). Suburbanización y periurbanización desbordaron la escala en la que el planeamiento se había concentrado en estos años, no sin generar, también, notables contradicciones internas.

Pronto, los valores de esa mirada - la del urbanismo urbano, reformista y social- serían también sustituidos en nuestro entorno por los nuevos principios de competitividad y de crecimiento que conllevaba la entrada del urbanismo neoliberal (López de Lucio 1993a) y los cambios que se producirían en el mercado inmobiliario. El problema de la ordenación urbana, de la construcción de la ciudad, fue cediendo ante el problema del suelo, convertido exclusivamente en gestión del mercado de suelo (Calderón \& García Cuesta, 2017; Roch, 2015). La alianza establecida entre gestión del mercado del suelo junto con los intereses de los sectores inmobiliario y bancario (Méndez, 2014; Naredo, 2010), conducirían al ciclo urbanizador expansivo de mediados de los años 90 (1er boom) y al posterior y más especulativo de los años 2000 (Lois et al., 2016; Rullán, 2012).

\subsection{Segundo período (1992-2008). La adopción de las políticas neoliberales, el gerencialismo y el urbanismo expansivo}

El segundo período se caracteriza por la amplia aplicación de los principios neoliberales que se ensayaron, especialmente, en la gestión y el gobierno de la ciudad. Los ayuntamientos y las administraciones locales fueron las primeras que aplicaron las nuevas formas de gobierno "gerenciales" y las fórmulas "empresariales" y de "marketing urbano" (Brenner et al., 2015). El uso de las formas gerenciales y fórmulas empresariales ya se fue desplegando a finales de la década de 1980. En ese período se ensayaban ya en algunas ciudades fórmulas de cooperación público-privada, especialmente a través de la gestión privada de los servicios públicos. Pero fue en la década de 1990 cuando se hizo evidente el giro hacia las formas y fórmulas neoliberales de gobierno y gestión de la ciudad (Gaja, 2015a; Díaz-Orueta et al., 2018). Por otro lado, el uso del marketing urbano se reveló como un instrumento polivalente ya que no sólo contribuía a la venta de la ciudad-mercancía preparándola para ser consumida, sino que también se convertía en una herramienta útil para "la construcción de consenso y legitimación social del modelo de ciudad y de los distintos proyectos para la ciudad" (AlcaláSantaella, 2004, pp. 310).

Las nuevas orientaciones se encaminarían a asegurar el crecimiento de las ciudades, a promover la competitividad y a implementar nuevas formas de gobierno local para afrontar los retos de la globalización económica (Méndez, 2014; Brenner et al., 2015). En vez de regular el 
crecimiento urbano, el urbanismo se dedicaría ahora a fomentarlo con todos los recursos que tenía a su alcance. ${ }^{9}$

La planificación convencional y el uso de planes y normas para reglamentar los usos del suelo parecían haber caído en total descrédito, pese a la madurez que estos habían conseguido en los años 90 (Ferrer, 2005). Por el contrario, la planificación estratégica y el desarrollo de proyectos urbanos eran considerados, cada vez más dentro del discurso neoliberal, como la única alternativa posible para que las ciudades afrontaran con éxito los desafíos de la competitividad global (Hall, 1996). Pareciera que, una vez resueltas las carencias básicas heredadas de la dictadura, algunos gobiernos locales empezaron a pensar en términos de estrategia urbana, definiendo objetivos y tratando de generar complicidades con actores económicos y sociales. Con ello, el urbanismo normativo/regulador se puso al servicio de la producción masiva de suelo, viviendas y artefactos urbanos, imponiéndose la visión de un urbanismo neo-desarrollista (Capel, 2013b; Romero et al., 2015).

Los principios clave de la ciudad neoliberal (desregulación, flexibilización, competitividad y privatización) fueron trasladados al urbanismo a través de las acciones siguientes: reclasificaciones y recalificaciones de suelo, desarrollo de grandes proyectos urbanos, privatización de los servicios urbanos básicos y los equipamientos públicos, y concesiones urbanísticas y mercantilización de áreas de alto valor expectante (García-Herrera, 2017; Bellet, 2017). Todas ellas permitiendo la apropiación privada de las plusvalías urbanas generadas desde lo colectivo y lo público (Rullán, 2012; Lois et al., 2016). Prácticas que, además de ser poco transparentes y nada democráticas, implicaron la despolitización del gobierno de la ciudad (Díaz-Orueta et al., 2018; Swyngedouw, 2018). Convenios y organismos de gestión (privados, semipúblicos, cooperación público privada, etc.) se convirtieron en el instrumento perfecto ${ }^{10}$ para flexibilizar y desregular las normas y los marcos de planificación. Se establecieron, así, una serie de prácticas ad hoc, un "urbanismo a la carta" para algunas grandes intervenciones y proyectos que se desarrollaban y funcionaban al margen (Gaja, 2008; Burriel, 2008). En su estudio sobre el reciente desarrollo urbano en Zaragoza, Escolano et al. (2018) apuntan que una de las características más notables del urbanismo desplegado en el municipio desde los años 2000 es la forma de convenios entre instituciones o empresas públicas para llevar a cabo

9 "La idea que predominaba era que la ciudad era una máquina de crear riqueza y que la función principal del urbanismo era engrasar la maquinaria" (Hall, 1996, p. 354).

10 Suelen ser procesos de decisión cerrados con convenios poco transparentes y complejos que pocas veces salen a la luz y en los cuales no hay procesos de participación (Díaz de Orueta, 2015; Bellet, 2017). 
grandes proyectos, -como por ejemplo la Plataforma Logística de Zaragoza (PLAZA), las obras derivadas de la implantación de alta velocidad ferroviaria en la ciudad (Zaragoza Alta Velocidad) o el consorcio Expo 2008-, o con agentes privados con los que, y según los autores, se han firmado en el marco del desarrollo del PGOU 2008 de Zaragoza 33 convenios entre el año 2000 y el 2016 (Escolano et al. 2018). La colaboración público-privada, muestra de una clara orientación neoliberal de la gobernanza urbana, fragmenta el proceso de toma de decisiones sobre la ciudad y transfiere competencias y servicios al sector privado.

Pero esto no ocurría sólo en las áreas metropolitanas y grandes ciudades del país. En otras muchas ciudades españolas de variadas dimensiones -incluso medias y algunas (las menos) pequeñas- se fue sustituyendo la política urbana y el urbanismo urbano por el marketing urbano, la planificación estratégica y la lógica de los grandes proyectos (Somoza, 2013).

\section{Figura 4. A Cidade da Cultura en Santiago de Compostela (izquierda) y el Centro Niemeyer de Avilés (derecha)}

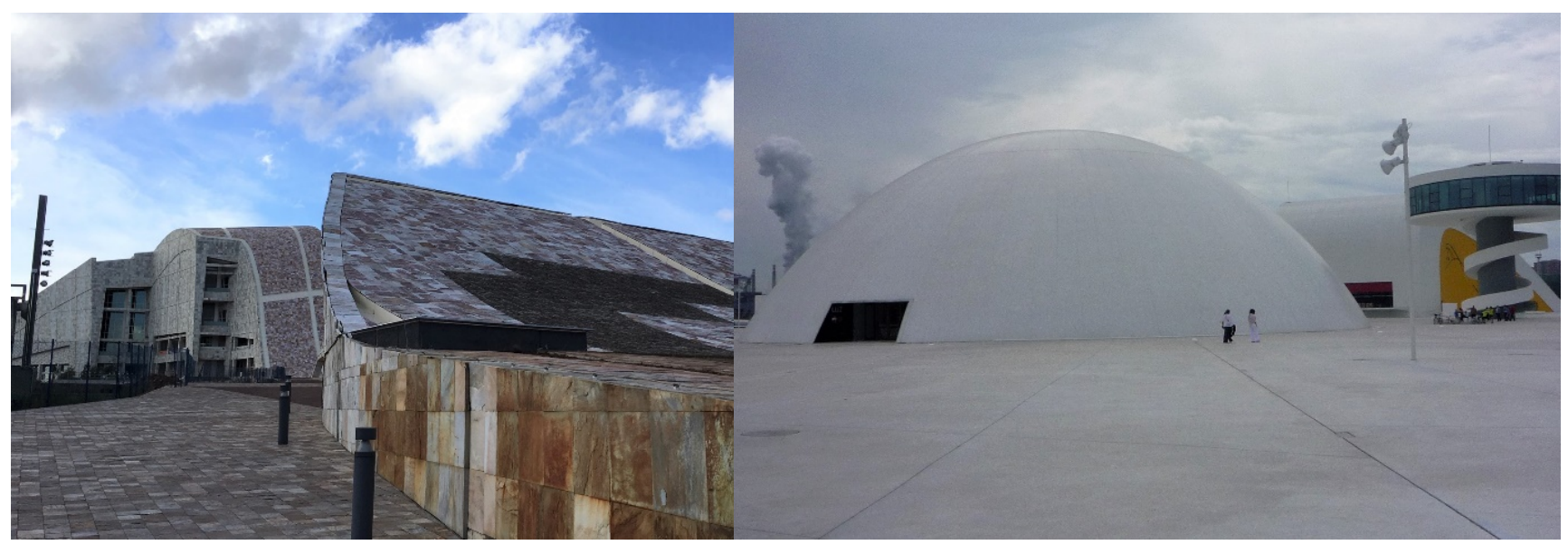

Fuente: fotografías de la autora (izquierda, 2018; derecha, 2011)

Como apunta Fernando Gaja: "Todas las ciudades, grandes, medianas o pequeñas han competido por dotarse de instalaciones culturales, deportivas, sanitarias, museos, teatros, auditórium, bibliotecas, y la interminable cadena de las "ciudades de": de la Justicia, de las Artes, de las Ciencias, de la Luz, de las Lenguas, etc." (Gaja, 2015a). El desarrollo de estos grandes proyectos, equipamientos, e infraestructuras, combinados con la fiesta de los grandes eventos, contribuyeron al endeudamiento público. Así se fueron creando espacios sobredimensionados (A Cidade de la Cultura en Santiago, la Ciutat de les Arts i les Ciències en València, la Ciudad de la Luz en Alicante); grandes equipamientos con poco uso (la Caja Mágica en Madrid), infraestructuras infrautilizadas, algunas cerradas o vendidas al mejor postor 
(las radiales de Madrid, aeropuerto de Ciudad Real, aeropuerto de Castelló de la Plana, aeropuerto de Lleida, etc.), todo ello muestra de una época de desvaríos y despilfarro (Romero González, 2019; Bellet, 2017).

En este período se promulgaron varias leyes que incidirían en la desregulación y liberalización del mercado del suelo. La Ley de 1990 de Régimen del Suelo y Ordenación Urbana, la posterior Ley 6/1998 de Régimen del Suelo y Valoraciones -también conocida como ley del "todo urbanizable" - o la Ley 6/1994, de 15 de noviembre, de la Generalitat Valenciana, Reguladora de la Actividad Urbanística (LRAU) contribuyeron a la masiva movilización de suelo urbanizado (Calderón \& García Cuesta, 2017).

La Ley estatal 6/1998, de 13 de abril, sobre régimen del suelo y venía a liberalizar el mercado del suelo al determinar que todo el suelo no protegido expresamente seria urbanizable. Con ello se eliminaba la prohibición de urbanizar el suelo que el Plan Municipal venía considerando como suelo no urbanizable común alimentando su transformación.

Por su parte, la LRAU valenciana introducía en 1994 cambios importantes en los planteamientos, estrategias e intervención en la producción del suelo que, Fernando Gaja, concreta en los siguientes: a) Se invertían las relaciones de poder entre los agentes urbanos, evitando que la propiedad del suelo fuera el elemento determinante; b) Se producía la mayor cantidad de suelo urbanizado posible, bajo la hipótesis de que ello redundaría en una reducción de su precio (hipótesis que ya se había demostrado repetidamente como falsa y que esta nueva experiencia venía a confirmar de nuevo); c) Creaba un nuevo agente urbano, "el urbanizador", 11 una especie de concesionario a quien se dota de poderes extraordinarios y que pasa a ser el agente central en el mercado del suelo (Gaja, 2015a). Con ello se venía a alterar las reglas del juego, las relaciones establecidas entre propietarios del suelo administración y promotores inmobiliarios.

Ambas leyes, por vías diferentes, incidían en la liberalización del mercado del suelo, vía planeamiento a través de cambios en la clasificación del suelo, a lo que se refiere la Ley

11 La figura del agente urbanizador nace con la Ley 6/1994, de 15 de noviembre, de la Generalitat Valenciana y, en mayor o menor medida, está recogida en la práctica mayoría de legislaciones autonómicas. El fin de la figura es gestionar el suelo de forma rápida para ponerlo en el mercado en condiciones de ser edificado (o sea, urbanizado) actuando al margen de los propietarios, lo que conllevaría un supuesto incremento de la oferta y una consiguiente bajada de los precios. Situación, esta última, que no se produjo por las rigideces del mercado, el comportamiento especulativo de los agentes y la falta de control. 
6/1988, o vía gestión a través del agente urbanizador de la ley valenciana, la LRAU (Ley 6/1994). Mecanismos que facilitaban la transformación del suelo y la urbanización generalizada.

La legislación promulgada en este período parece pues basarse en la concepción que hacer ciudad consiste, esencialmente, en explotar el valor del suelo al convertirlo en urbanizable (Calderón \& García Cuesta, 2018; Burriel, 2009), promoviendo con ello la nueva ocupación y urbanización del suelo frente a la preservación y rehabilitación de los tejidos y patrimonio ya construido (Fariña \& Naredo, 2010).

En este contexto nos encontramos con Planes Generales que, primero, abandonan los intentos de ordenación integral y relajan los planteamientos a largo plazo alegando buscar una mayor flexibilidad y eficacia. Segundo, los Planes pasan a contemplar altísimas expectativas de crecimiento y prevén notables cantidades de suelo urbanizable (delimitado y especialmente no delimitado). Ejemplo de ello son los datos que ofrece la Tabla 1.

\section{Tabla 1. Estructura del suelo y potenciales de crecimiento del Planeamiento General vigente en los municipios de más de 10000 habitantes $(2018)^{12}$}

\begin{tabular}{|l|r|r|r|r|}
\cline { 3 - 5 } \multicolumn{1}{c|}{} & Suelo Urbanizable & Suelo Urbanizable & Suelo & $\begin{array}{c}\text { Superficie de las } \\
\text { áreas de }\end{array}$ \\
\cline { 1 - 5 } $\begin{array}{l}\text { Período } \\
\text { aprobación } \\
\text { planeamiento }\end{array}$ & Delimitado & No Delimitado & Urbano & desarrollo (ha) \\
\hline $1979-1991$ & 31536 & 18122 & 58909 & 35297 \\
\hline $1992-2008$ & 163583 & 193618 & 271668 & 201590 \\
\hline $2009-2018$ & 53610 & 35832 & 107176 & 69115 \\
\hline
\end{tabular}

\begin{tabular}{|l|r|c|c|}
\cline { 2 - 4 } \multicolumn{1}{c|}{} & $\begin{array}{c}\text { Total de viviendas } \\
\text { Previstas }\end{array}$ & $\begin{array}{c}\text { Ratio Suelo urbanizable } \\
\text { delimitado/ } \\
\text { suelo urbano }\end{array}$ & $\begin{array}{c}\text { Ratio Suelo } \\
\text { urbanizable total/ } \\
\text { suelo urbano }\end{array}$ \\
\hline $1979-1991$ & 630372 & 0,5 & 0,8 \\
\hline $1992-2008$ & 3883800 & 0,6 & 1,3 \\
\hline $2009-2018$ & 1422638 & 0,5 & 0,8 \\
\hline
\end{tabular}

Nota: Las Áreas de Desarrollo, a efectos del SIU, se corresponden con aquellos ámbitos o sectores delimitados por el planeamiento en los que éste prevé transformaciones urbanas y ha establecido las condiciones para su desarrollo.

Fuente: elaboración propia a partir de los datos del Sistema de Información Urbana del Ministerio de Fomento (2018)

12 Se han seleccionado sólo los municipios con planeamiento municipal de primera escala (Planes Generales, Delimitaciones de Suelo o Normas Subsidiarias de Planeamiento) vigente y aprobado después de 1978 de más de 10000 habitantes y depurado la fuente eliminando aquellos registros municipales en los que la información es deficiente. En conjunto se ha trabajado con 701 registros de los 751 municipios que en 2018 cuentan en España con más de 10000 habitantes. 
El 64 \% de los municipios de más de 10000 habitantes de la base del Sistema de Información Urbana (SIU) (ver nota 12) tienen aprobado el documento de planeamiento vigente en el período 1992-2008, el período durante el cual se produce el tsunami urbanizador. ${ }^{13}$ Estos sumaban un total de $357200 \mathrm{Ha}$ de Suelo urbanizable (delimitado o sectorizado y no delimitado) y contaban con un total de 201590 Ha de superficie en Áreas de Desarrollo. En conjunto el indicador de expansión urbanística (la relación suelo urbanizable/suelo urbano), y que resulta clave en el modelo de crecimiento que dibuja el planeamiento municipal general (Plan General, Normas Subsidiarias de Planeamiento, Delimitaciones de Suelo), presenta una relación de 1,3. Ello es una buena muestra de las expectativas de crecimiento del planeamiento en buena parte de los municipios del país en el período 1992-2008. Si nos centramos en el indicador suelo urbanizable delimitado o sectorizado ${ }^{14}$ sobre suelo urbano la cifra queda en un 0,6 , pero son muchos los municipios en los que esta misma ratio se sitúa por encima del 1. En un 19,6\% de los municipios (de los 449 con planeamiento aprobado en el período) se supera esa cifra siendo su perfil y localización diversa. Sin embargo, destacan por sus expectativas de crecimiento los siguientes:

- Municipios de claro perfil turístico en primera o segunda línea de costa: Ayamonte, Huelva; Vila Joiosa; Alicante; Guardamar del Segura, Alicante; Estepona, Málaga; Conil de la Frontera, Cádiz; Burriana, Castelló de la Plana; Granadilla de Abona, Santa Cruz de Tenerife; Chipiona, Cádiz; Mutxamel, Alicante; Rota, Cádiz. En todos ellos, de mayor a menor, el indicador es superior al 1,5.

- Municipios localizados en la periferia de diferentes áreas metropolitanas o en el área urbana de su influencia de entre los que destacan: en el caso de Madrid: Arroyomolinos, Seseña (Toledo), Parla, Ciempozuelos, San Martín de la Vega o Villanueva del Pardillo); en València: Llíria o Riba-roja de Túria; y en Sevilla: Bollullos de la Mitación.

- Por sus abultadas cifras cabe destacar muchos municipios de la Comunidad de Murcia. De entre ellos destacar los casos de Cieza, Lorca, Santomera, Fuente Álamo, Caravaca de la Cruz, Alhama de Murcia, Molina de Segura, todos ellos con un indicador de expectativa de

13 Se trata de 449 municipios (de los 701 de la base de datos creada con municipios de más de 10000 habitantes) que según el Padrón de 2018 alojaban 22195568 de personas y contaban con 56646 km².

14 El mismo SIU establece que el: "Suelo urbanizable delimitado o sectorizado se corresponde con el suelo programado para su transformación e incorporación en el tejido urbano, comprende los terrenos delimitados por el planeamiento para su integración en la malla urbana y en los que haya establecido las condiciones para su desarrollo a través de un proceso de transformación por la urbanización en los plazos temporales previstos en el correspondiente programa" (SIU, 2018, p. 10). 
crecimiento a corto y medio plazo (Suelo Urbanizable Delimitado en relación al Suelo Urbano) por encima del 2, es decir, en estos últimos casos el Suelo Urbanizable Delimitado aprobado por planeamiento municipal de primera escala permitiría doblar la superficie de suelo urbano.

- Importantes son también los indicadores de un buen número de capitales de provincia: Toledo (con un 2,1); Badajoz (con un 1,6); Cuenca (con un 1,6); Murcia (1,6); Ciudad Real $(1,3){ }^{15}$ o Segovia $(1,1)$. El caso de Toledo es uno de los más estudiados de entre los municipios destacados en este último apartado (Zarate Martín, 2007; Muelas \& Parrilla, 2008; Escudero, 2018). Los datos del municipio se corresponden al Plan de Ordenación Municipal, aprobado en 2007, pero anulado en 2017 por la Consejería de Fomento de la Comunidad de Castilla-La Mancha tras el fallo de varias sentencias de la Sala de lo Contencioso-Administrativo del Tribunal Superior de Justicia de Castilla-La Mancha (TSJCM), continua vigente el Plan General de 1986. Luís Alfonso Escudero comenta sobre el caso de forma concluyente: "El POM de 2007 aplica una lógica desarrollista" (Escudero, 2018, pp. 320).

Figura 5. Clasificación de suelo alrededor del núcleo urbano principal del término municipal de Badajoz (Plan General Municipal de Badajoz, 2007)

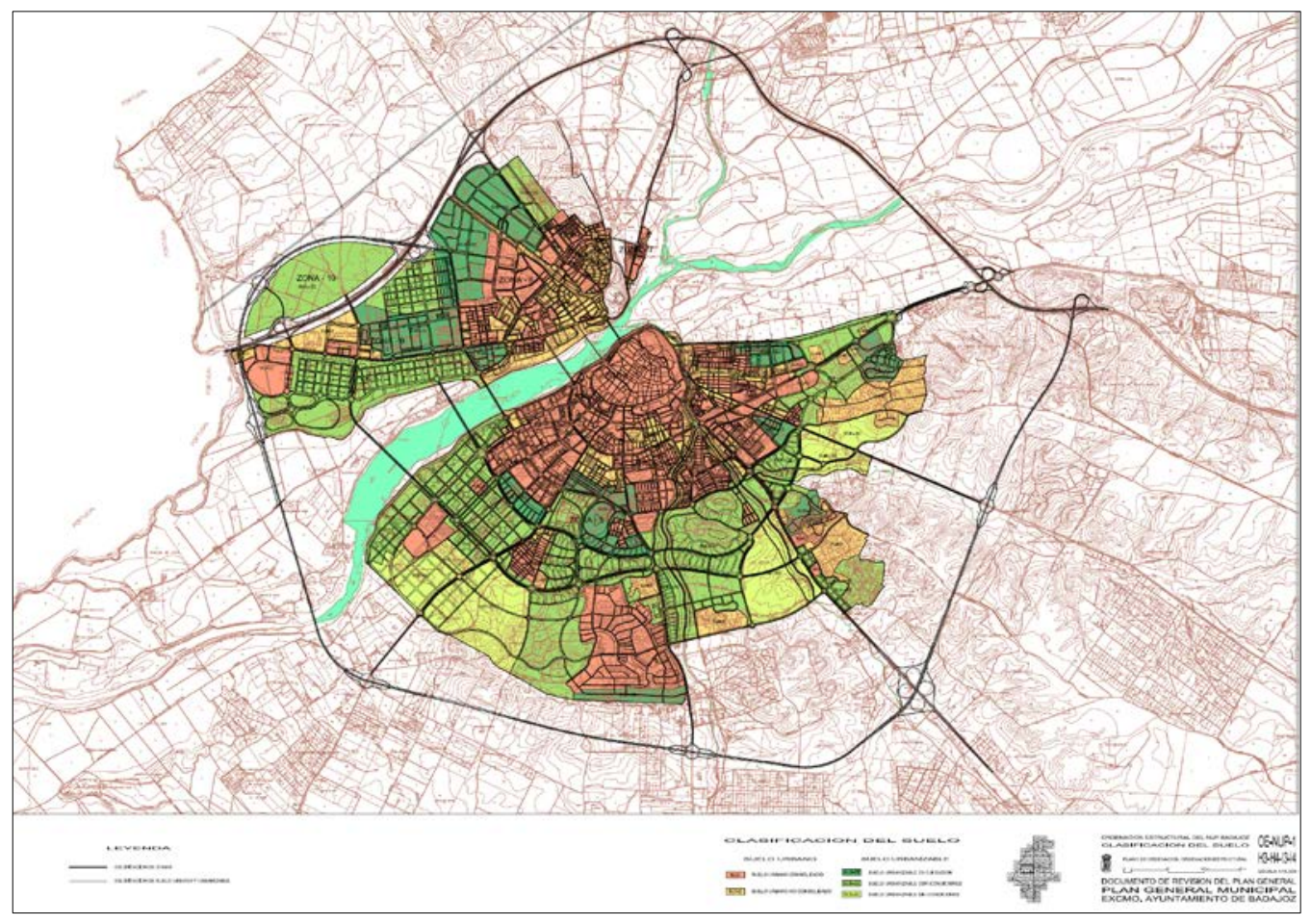

Fuente: Ayuntamiento de Badajoz (2007)

15 Miguelturra, municipio conurbado con Ciudad Real, presenta también un alto índice con un 2,1. 
En el caso de Badajoz, los datos presentados provienen del Plan General aprobado en 2007 del que se adjunta detalle de la clasificación alrededor del núcleo principal del municipio en la Figura 4. Del análisis de los datos del SIU podemos concluir que las áreas de desarrollo previstas en el Plan (Suelo Urbanizable más Suelo Urbano no consolidado) sumaban en Badajoz un total de $4156 \mathrm{Ha}$ y que los sectores de desarrollo con uso residencial permitirían un potencial de construcción de 61809 nuevas viviendas, siendo el parque de vivienda existente en 2011 de 72067.

Estas amplias expectativas de crecimiento del planeamiento general municipal aprobado entre 1992 y 2008 se traducen en un elevado potencial de viviendas previstas que, en la muestra de municipios de más de 10000 habitantes obtenida a través del Sistema de Información, llegan a más de 3800000 viviendas.

La aprobación y posterior desarrollo de innumerables Planes Parciales y proyectos de urbanización, alimentarían a escala local la puesta en el mercado de grandes cantidades de suelo.

Como ya ha sido profusamente estudiado, se produjo en España, desde finales de la década de 1990 del pasado siglo y con algo de retraso respecto a las economías occidentales más centrales, la última fase expansiva de la economía de claro tinte especulativo. Esta expansión económica, que tuvo su máxima expresión en lo inmobiliario y en el sector de la construcción, venía ya siendo alimentada por la aplicación del Real Decreto Ley 2/1985, de 30 de abril, sobre Medidas de Política Económica (más conocido como Decreto Boyer) que, entre otras, estableció un conjunto de medidas destinadas a estimular el consumo privado y la inversión, dirigiéndolos hacia lo inmobiliario, el mercado de suelo y la vivienda.

Coincidiendo con el cambio de gobierno en 1996 - con el triunfo electoral de la derecha neoliberal- se aceleró el crecimiento económico. Esta circunstancia, junto con la adopción de la moneda única europea y la estricta política monetaria, contención de la inflación y de los tipos bancarios desplegada desde Bruselas, contribuyó a la eclosión del nuevo boom inmobiliario (1997-2008) (López \& Rodríguez, 2010). El llamado "tsunami urbanizador" y por otros "la década prodigiosa del urbanismo español" (1997-2008) estaban en marcha, auspiciados desde lo público a través de la legislación urbanística, la política económica y fiscal favorables, así como unas finanzas locales dependientes. Muchos de los gobiernos locales alentaron además estos procesos ya que los recursos asociados a la urbanización y al desarrollo de suelo eran utilizados para financiarse en un contexto de dificultades para la financiación municipal. La 
intensidad del proceso de urbanización, desarrollista y altamente especulativo, implicó un altísimo desarrollo de suelo especialmente dedicado a infraestructuras (muchas de ellas de alta capacidad: autovías, tren de alta velocidad, aeropuertos, etc.), a usos residenciales y a actividades económicas (parques empresariales, polígonos logísticos, parques tecnológicos, etc.).

A título de ejemplo, entre 2000 y 2011, y según datos del Corine Land Cover (CLC), la superficie artificial aumentó en España en $381962 \mathrm{Ha}$, lo que supone un incremento del 4,3\% anual, a razón de unas 95 ha diarias (Olazabal, 2018). Un ritmo de crecimiento muy superior al que se registra en población y vivienda como se muestra en la Tabla 2.

\section{Tabla 2. Dinámica comparada de artificialización del suelo, población y parque de viviendas}

\begin{tabular}{|c|c|c|c|}
\hline Valores absolutos & Población & Parque de viviendas & Suelo artificializado \\
\hline 1987 & 38731578 & $(1981) 17220399$ & 647509 \\
\hline 2000 & 40499791 & 20946554 & 811565 \\
\hline 2011 & 47190493 & 25208623 & 1193705 \\
\hline 2018 & 46722980 & $(2001) 25712744$ & 1254976 \\
\hline Incrementos anuales & Población & Parque de viviendas & Suelo artificializado \\
\hline $1987-2000$ & 0,4 & 2,4 & 1,9 \\
\hline $2000-2011$ & 1,5 & 1,8 & 4,3 \\
\hline $2011-2018$ & $-0,14$ & 0,3 & 0,7 \\
\hline
\end{tabular}

Fuentes: Censos de Población y Viviendas (1981, 2001, 2011); estimación del Parque de

Viviendas del Ministerio de Vivienda (2018); Corine Land Cover (1987, 2000, 2011, 2018)

Los efectos de esta singular expansión también han sido destacados en numerosos trabajos (Burriel, 2008; Romero, 2010; Rullán, 2012; Gaja, 2015b; Méndez \& Plaza, 2016; Méndez et al., 2016; entre otros). La única reflexión que se pretende añadir aquí es lo paradójico que pudiera parecer el hecho que en el momento de mayor regulación urbanística y territorial del país se produjera el mayor proceso de urbanización de la historia. ${ }^{16}$

La herencia del período legó planes con previsiones de crecimiento desmesuradas, proyectos urbanos fuera de escala y, sobre todo, grandes cantidades de suelo urbanizado o desarrollos sin

16 Calderón y García apuntan al respecto:"... si bien nunca en España las leyes y los planes de ordenación han sido de mejor factura técnica y calidad documental (...), lo cierto es que tampoco han sido eficaces para cumplir con el propósito declarado en la ya vieja ley sobre el Régimen del Suelo y Ordenación Urbana de 12 de mayo de 1956, luchar contra la especulación, (...) tampoco se alcanzaron los dos grandes objetivos propuestos en la última generación de leyes sobre urbanismo en España (1998-2007): la simplificación normativa y la reducción del precio de suelo y vivienda" (Calderón \& García Cuesta, 2017, p. 2). 
consolidar que se prodigaron a lo largo y ancho del país. ${ }^{17} \mathrm{Y}$, así, persisten aún por doquier paisajes del pinchazo de una burbuja inmobiliaria que generó una fuerte crisis económica, social y política, cuyas consecuencias llegan hasta nuestros días.

Otra de las características destacables del urbanismo del período es la protección del medio, del paisaje y del patrimonio urbano que sin embargo en muchos casos se convierten con demasiada frecuencia en otra posibilidad de negocio a través de su propia mercantilización (Fernández Salinas, 2005; Tomé, 2007). Un buen ejemplo es el desarrollado por Gabino Ponce sobre el centro histórico de Orihuela, un centro con un alto valor patrimonial (Ponce, 2018). La hipótesis que el autor desarrolla en el trabajo -y que podríamos aplicar a otros muchos casos- es que la recuperación del área se fue orientando más al negocio inmobiliario y extracción de rentas que hacia la recuperación y dinamización del espacio, entendido éste como espacio social. La aprobación en 1994 del Plan Especial de Ordenación y Protección del Centro Histórico de Orihuela desplegaba la figura ya prevista en el Plan General de 1990. Al respecto el autor apunta que "las operaciones públicas y privadas se han orientado hacia la recuperación del mito del centro histórico, tanto o más para su puesta en valor turístico, que como producto social coherente (Ponce, 2018, p. 205). Boira comenta contemplando otros casos valencianos (Alicante, València y Alcoy) que "la intervención pública en rehabilitación de centros históricos parece haber alcanzado mucho más éxito en los aspectos arquitectónicos o urbanísticos que no en los sociales y funcionales" (Boira, 1995, p. 256).

En conjunto, el cambio de lógica y modelo provocó una mayor ruptura y fragmentación espacial, especialmente en las ciudades pequeñas y medias del interior que partían de estructuras menos complejas, más ligadas a lógicas locales y con espacio-temporalidades más vinculadas a lo cotidiano (Bellet, 2017). Además, todo ello profundizó en la diferenciación socio-espacial urbana y acabó lastrando las ya menguantes finanzas municipales (Nel.lo, 2015; Subirats, 2016).

\subsection{Tercer período (2008-2013). La crisis, la reformulación de las políticas urbanas y las nuevas agendas locales}

La explosión de la burbuja inmobiliaria en 2008 y la profunda crisis, impulsada en buena parte por el desplome del sector de la construcción, sacaron a la luz lo que había tras el espejismo del crecimiento (Burriel, 2014). Como resultado de la crisis, el alto desempleo y el aumento de las desigualdades sociales, crecían en paralelo al programa de reformas llevadas a cabo por el

17 Estos paisajes devastados repletos de cadáveres inmobiliarios son caracterizados con una gran agudeza en el libro de Julia Schulz-Dornburg (2012). 
Estado y la Unión Europea bajo el discurso de la austeridad. Las reformas implicaron recortes presupuestarios, la profundización en la aplicación de las políticas neoliberales y la recentralización de las políticas (especialmente las relacionadas con el bienestar) a costa de los gobiernos regionales y locales (Martí-Costa \& Tomàs, 2016). Este proceso estuvo acompañado por el agravamiento de la crisis social y la deriva política, cuyas consecuencias son aún hoy palpables (Díaz-Orueta et al., 2018).

En esta etapa, se avanza un paso más en el proceso de mutación neoliberal del Estado, dónde la gestión de lo social quedó claramente subordinada a los intereses financieros. A escala local, se afianza un proyecto de nueva ciudad dirigido a promover la competitividad en el que se consolida una estructura de clases cada vez más polarizada y un modelo de gobernanza autoritario (Díaz-Orueta et al., 2018; Iglesias et al., 2014). La crisis obliga al replanteamiento del modelo expansivo anterior $y$, aparentemente, vuelve a surgir el discurso del "urbanismo urbano", pero esta vez claramente orientado a explotar las plusvalías de los espacios mejor localizados, los centrales. Operaciones centrales que trata de amparar e impulsar la Ley 8/2013, de 26 de junio, de rehabilitación, regeneración y renovación urbanas (conocida como la Ley de las tres R) (Calderón \& García Cuesta, 2017). Tras la crisis, las nuevas estrategias inmobiliarias parecen abandonar las grandes operaciones en la periferia y dirigirse al desarrollo de proyectos más modestos en el interior de la ciudad que, a través de la rehabilitación o renovación, provocarán fuertes cambios funcionales y del perfil socioeconómico de la población generando desplazamientos y gentrificación física y simbólica (García-Herrera, 2017). En paralelo, se van recuperando algunos grandes proyectos que contribuyen a consolidar una ciudad de fragmentos, privativa y colonizada por el capital financiero (Bellet, 2017; Romero et al., 2015). El caso de la operación Chamartín es un buen ejemplo de ello. Se trata de la mayor intervención de regeneración urbana de Europa en la actualidad, cuyos principales promotores son el BBVA y el grupo San José (Brandis, 2019). El proyecto contempla cifras astronómicas: un ámbito de actuación de 2,3 millones de metros cuadrados (230 ha) de unos 5,6 km de largo de norte a sur, desde los entornos de la Plaza Castilla hasta las primeras estribaciones del Monte del Pardo. La macrooperación actuará sobre cinco ámbitos: tres para usos residenciales y equipamientos que se concretan en 10500 viviendas (un $20 \%$ viviendas sociales) para ser construidas en las zonas de Fuencarral-Malmea, Fuencarral-Tres Olivos y Fuencarral-Las Tablas, al norte de la M-30; un segundo ámbito, al sur de la M-30, dónde el terciario será el gran protagonista con más 1000000 de $\mathrm{m}^{2}$ de edificabilidad (el Centro de Negocios); y un tercero que es la propia estación de Chamartín, con una ordenación específica aún por definir. En conjunto representa 
una edificabilidad de $2662500 \mathrm{~m}^{2}$. El proyecto, que ha ido apareciendo y dejándose encima de la mesa en estos últimos 25 años, fue retomado por la anterior legislatura bajo el gobierno de Ahora Madrid que logró aprobarlo inicialmente, con un notable revuelo como muestran las más de 3500 alegaciones presentadas al mismo, pero no logró aprobarlo de forma definitiva antes de las elecciones municipales del 26 de mayo de 2019. A principios de enero de 2020, y con el nuevo consistorio municipal surgido de esas últimas elecciones, el proyecto sigue su andadura a la espera de su aprobación definitiva por parte de la Comunidad de Madrid.

Figura 7. La propuesta de usos del suelo en la macro-operación Madrid Nuevo Norte (antes llamada Operación Chamartín)

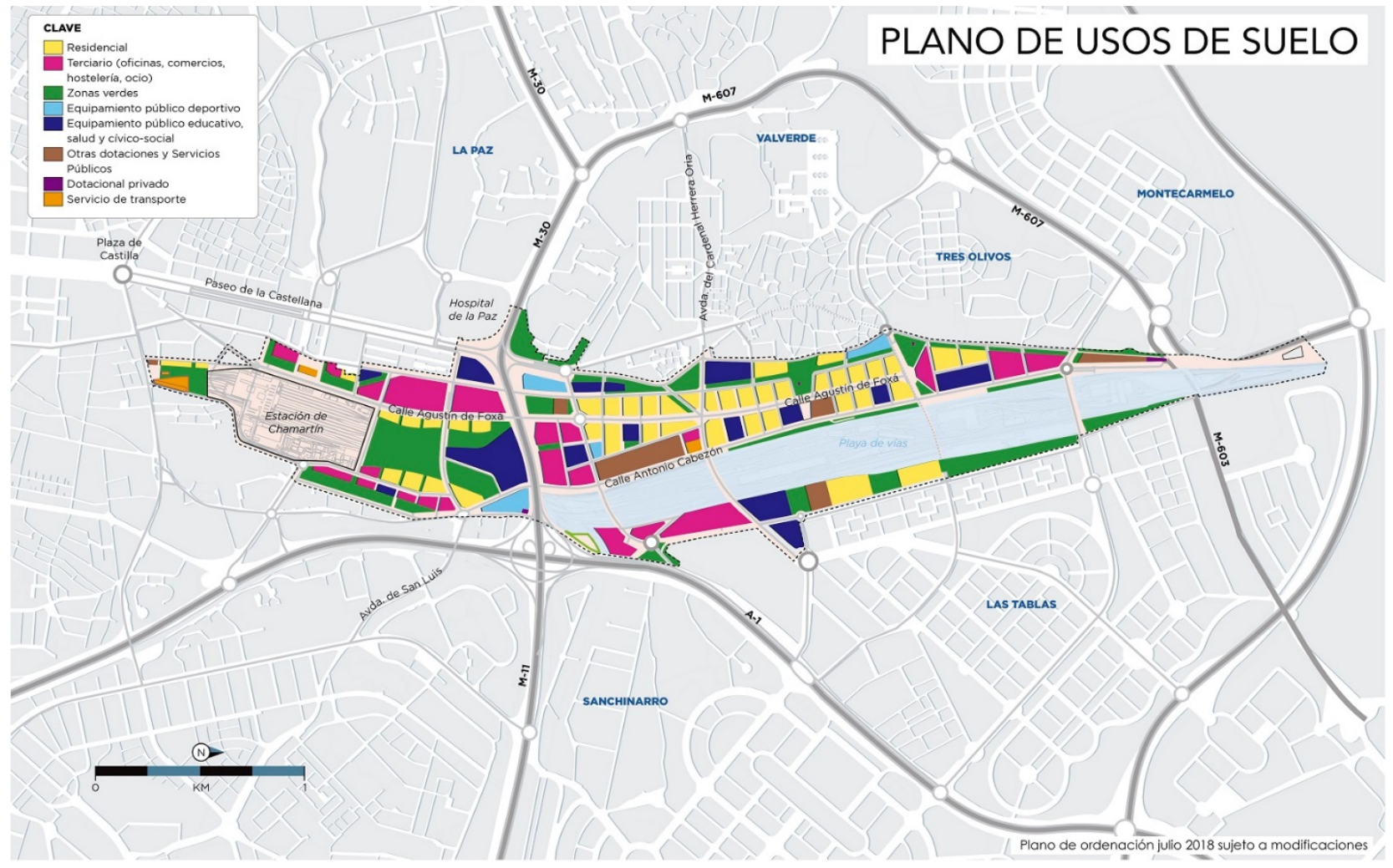

Fuente: Distrito Castellana Norte Madrid (n.d.)

Estas actuaciones coexisten con el resurgir de un buen número de intervenciones que cuestionan el modelo y se presentan como alternativa al mercado y a las actuaciones institucionales realizadas a través de la autogestión: ocupaciones, gestión cooperativa de viviendas y equipamientos públicos, etc. Se trata de respuestas planteadas por colectivos urbanos que contestan el modelo neoliberal de ciudad delante de la ausencia y retirada de las políticas públicas. Paradójicamente, estas interpelaciones inspirarán algunas de las nuevas políticas municipales. 


\section{Figura 8. Intervención en los alrededores del Mercat de Sant Antoni (Barcelona)}

en el marco del programa Superilles

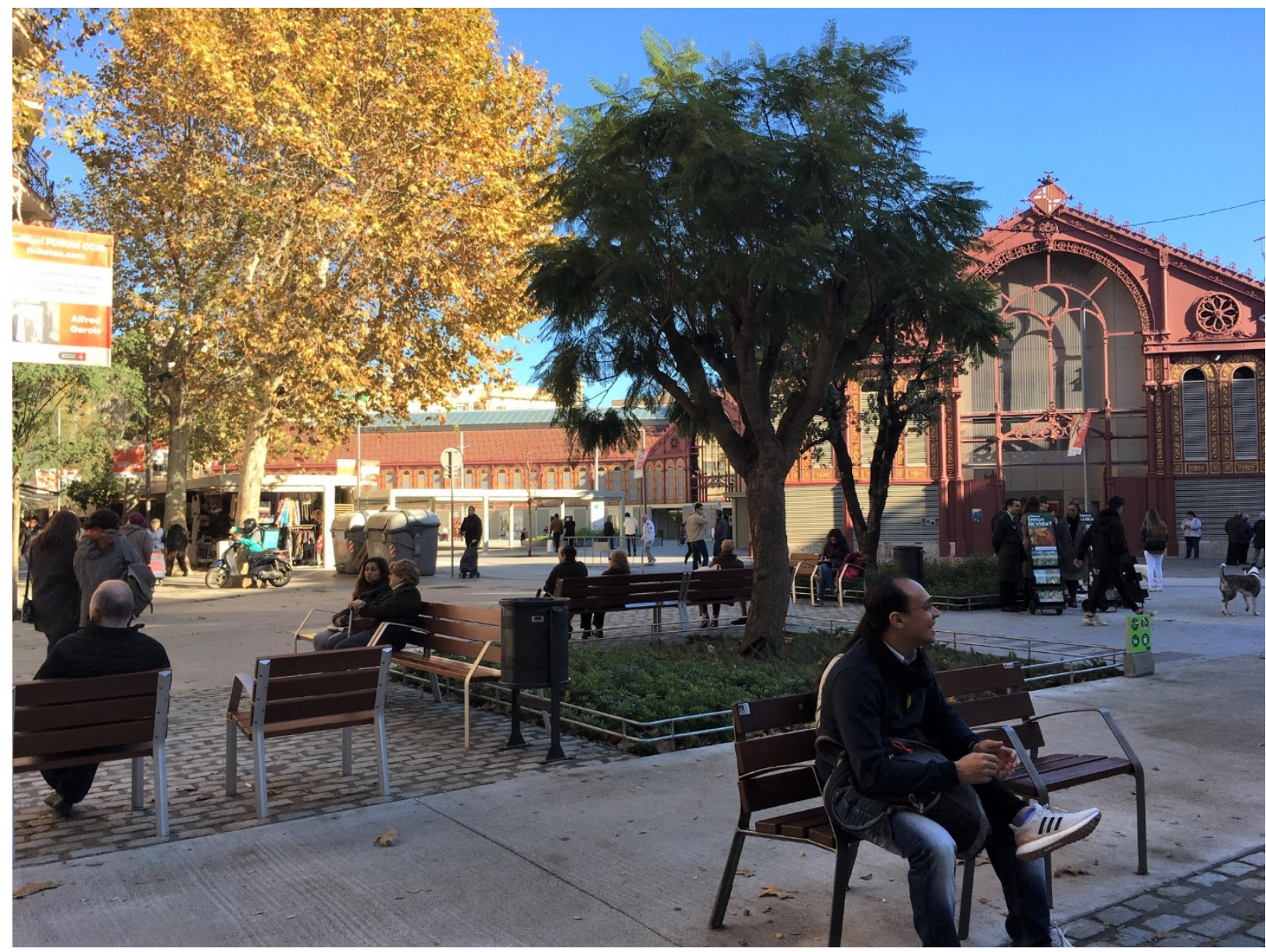

Fuente: fotografía de la autora (noviembre de 2018)

Buena parte de los cambios experimentados por el "nuevo urbanismo" se fundamenta en los cambios culturales y sociopolíticos que, ya desde antes de la crisis, se han ido produciendo en el país y que cristalizan de forma clara en la fuerte movilización social del 15 M de 2011 y en la aparición de las nuevas formaciones políticas, que empezaron a implicarse en el gobierno local en las elecciones municipales de 2015. Estos movimientos demandaban, entre otras, nuevas formas de gobernanza local -menos tecnocráticas y más basadas en la participación directa de la ciudadanía en la producción y gestión de lo público y de la ciudad- y nuevas políiticas más próximas a los problemas cotidianos de la ciudadanía. ${ }^{18}$ Las demandas incidirán en la construcción de las agendas políticas de los nuevos ayuntamientos, especialmente en aquellos

18 Uno de los puntos centrales de esas nuevas demandas es el de la vivienda, tema que rebasa el marco del trabajo. 
en los que se incorporaron las nuevas formaciones políticas. ${ }^{19}$ En otros muchos municipios, se va introduciendo, a su vez, alguna de esas nuevas miradas en la configuración de las nuevas agendas políticas (Martí-Costa \& Tomàs, 2015).

¿Cómo se podrían caracterizar esas nuevas políticas municipales (también las urbanísticas) desplegadas especialmente desde lo que se llamaron "ayuntamientos del cambio" pero también en muchos otros ayuntamientos? En general, y en base a las intervenciones municipales citadas al final de este apartado y a los detallados en los trabajos de Paisaje Transversal (2018) y LaCol (2018), cabría destacar lo siguiente:

- Las políticas urbanas se vuelven más plurales y complejas abordando aspectos sociales, culturales y ambientales, todo ello sin abandonar la vertiente urbanística-económica. Muchas de las acciones o intervenciones serán más integrales, abrazando disciplinas muy diversas y difíciles de encajar en una sola política sectorial.

- Las nuevas intervenciones se establecen a partir de criterios espaciales/territoriales (dinamización de barrios vulnerables, regeneración de centros históricos, etc.), criterios temáticos (género, exclusión, inmigración, etc.), franjas de edad (jóvenes, personas mayores, etc.), o se dirigen a colectivos específicos (familias monoparentales, discapacitados, etc.).

- La implicación de la ciudadanía en la gestión de lo público deviene prioritaria y, en muchas ocasiones, conlleva nuevas formas de coordinación vertical (entre las instituciones) y horizontal (ciudadanía). Interesa, pues, desarrollar procesos participativos que incluyan la presencia y acción de la ciudadanía en todas las fases de la intervención, desde su diseño hasta su ejecución y valoración final.

Además, y en lo referente específicamente a las políticas urbanísticas, los cambios apuntan hacía las siguientes acciones y criterios preferentes:

- Cierta desconfianza a los proyectos tecnocráticos, promoviendo ensayos con metodologías participativas que intentan superar lo meramente consultivo. Esta es una de las líneas en la que más se trabajó en los "ayuntamientos del cambio", aunque el balance de esas prácticas está aún por hacer. El peligro de la generalización de las prácticas participativas es que se

19 En las elecciones municipales de 2015, las nuevas formaciones políticas llegan al gobierno municipal, muchas veces en coalición con otros partidos, en grandes ciudades como Barcelona, Madrid, València, Zaragoza, Cádiz, A Coruña; en ciudades medias-grandes como Pamplona, Valladolid, Alicante, Córdoba o Vitoria-Gasteiz; y en otras ciudades medias como Huesca, Castelló de la Plana, Ciudad Real, Toledo, Oviedo o Zamora, entre otras. Aunque existen diferentes asimetrías de poder en cada una de las coaliciones, todas ellas pretendían recoger, en parte, el legado de las movilizaciones sociales del 15M. 
conviertan en una cuestión retórica de legitimación, mercadotecnia o en un medio para crear consensos pasivos (Paisaje Transversal, 2018).

- La atención al diseño y producción/reproducción del espacio a otra escala: unidad vecinal, el área ambiental, la unidad de paisaje, el barrio o distrito, entre otras. Se potencian las escalas intermedias de actuación que se erigen en un sujeto político y en un asidero instrumental para desplegar un enfoque integrado de la acción urbanística (Rivas et al., 2017).

- La preferencia por el desarrollo de pequeñas actuaciones bajo una estrategia común que manifiesta una clara tendencia a la recuperación del espacio público para la ciudadanía y a la mayor atención a los ritmos y necesidades de la ciudad más cotidiana (LaCol, 2018).

- El valor de lo procesual y la experimentación como modo de iniciar un proceso colectivo de transformación. Las nuevas intervenciones se constituyen, así, en un sistema de temporalidades, que articulan objetivos firmes, decisiones flexibles y actuaciones inmediatas (Paisaje Transversal, 2018).

En esas grandes líneas de actuación, encajan programas e intervenciones municipales como, primero, los programas de revitalización de solares urbanos vacíos ("Esto no es un solar" en Zaragoza; "Re-gen" en Huesca o el "Pla de Buits" en Barcelona) (Bellet, 2014); segundo, los procesos de participación ciudadana para el diseño y programación de usos en espacios públicos, como los de Plaza España en Madrid o los de La Rambla en Barcelona; tercero, el proyecto de las "Superilles" en Barcelona, una estrategia que trata de recuperar el espacio público a través de su revitalización y de la pacificación del tránsito, a partir de procesos de participación ciudadana (Agencia de Ecología Urbana de Barcelona, 2016); o, cuarto, los programas "Sumem des dels barris" de Olot (Girona) y "Pla de Barris" de Barcelona, que se dirigen a la dinamización de barrios vulnerables a partir de procesos de participación ciudadana y acciones transversales.

\section{Reflexiones finales}

Las políticas urbanísticas en los últimos 40 años de ayuntamientos democráticos han ido cambiando de la inicial exigencia de regular las actividades y ordenar el crecimiento (de 1979 a primeros de los años 90), a facilitar, el desarrollo urbano y la producción inmobiliaria a través de un tipo de urbanismo expansivo (entre 1993-2007), para llegar, en la actualidad, a un urbanismo en el que coexiste la tendencia anterior mientras, y en paralelo, se ensaya con un nuevo urbanismo que se tilda de participativo, transversal y menos tecnocrático. 
Con el despliegue de las políticas neoliberales en los años noventa entraron en crisis los paradigmas tradicionales basados en el plan y el urbanismo normativo que se vieron superados por la planificación estratégica y la lógica de los grandes proyectos. La llegada de la crisis y los nuevos planteamientos surgidos a partir de las movilizaciones del 15M de 2011 contribuyeron a poner en cuestión el modelo de ciudad y el tipo de urbanismo desplegado durante el boom inmobiliario, al que se acusó de tecnocrático y de falto de transparencia. Surgieron, así, algunas iniciativas que venían a modificar contenidos, formas y métodos del urbanismo y planificación urbana tradicional, adoptando nuevas formas de gobierno que han convivido, desde entonces, con los viejos modelos y lógicas de mercado de la ciudad neoliberal.

Faltan, todavía, estudios más detallados y balances comparados del legado de estas acciones y políticas recientes desplegadas en el último período. $Y$ aunque estas no han logrado, hasta el momento, presentar un modelo alternativo, al menos sí han conseguido cambiar el foco de algunas agendas urbanísticas municipales hacía los problemas de la vida cotidiana y ensayar con nuevas fórmulas de gobierno más participativo.

Pero nos preguntamos, siguiendo a Neil Brenner (2018, p. 572) si alguna de estas acciones, no serán simplificaciones despolitazadas, "... promovidas de forma agresiva por una variedad de actores corporativos y promotores inmobiliarios para quienes la construcción de ciudades globales, ciudades inteligentes, ciudades creativas, ciudades sostenibles, ciudades ecológicas, y similares, es vista como el camino óptimo para asegurar un crecimiento económico continuo sin alterar la formación hegemónica actual de acumulación, neoliberalizada y financiarizada, por desposesión", (Neil Brenner, 2018, p. 572) (traducción de la autora). ¿No acaban algunas de estas intervenciones y acciones "participacionistas" convirtiéndose también en simplificaciones despolitizadas de un necesario debate más profundo sobre las ciudades que queremos y los procesos de producción que las guían?

La lógica del urbanismo inmobiliario y del urbanismo a la carta sigue estando hoy muy presente en nuestras ciudades pese a presentarse, una vez y otra vez, como un modelo agotado. Sin embargo, y a diferencia del período anterior, las nuevas actuaciones son mayoritariamente centrales y altamente estratégicas, guiadas por los principios de acumulación del capitalismo financiero global. Se consuma así un urbanismo extractivo que multiplica la lógica de la ciudad de fragmentos. 
Agradecimientos: El presente trabajo ha sido posible gracias al proyecto "Evolución de las políticas urbanísticas en ciudades medias españolas y sus áreas urbanas: 1979-2019" (RTI2018096435-B-C21), financiado por el Ministerio de Ciencia e Innovación, en la convocatoria Proyectos I+D+i "Retos de Investigación" de 2018 (Gobierno de España).

Declaración responsable: La autora declara que no existe ningún conflicto de interés con relación a la publicación de este artículo. La autora ha asumido todas las tareas para su redacción y publicación a excepción de la obtención de datos del Corine Land Cover, realizada por Eduardo Olazabal. 


\section{Bibliografía}

Agencia de Ecología Urbana de Barcelona (2017). Programa de Supermanzanas en Barcelona. Barcelona: Ajuntament de Barcelona. Retrieved from

http://www.ajuntament.barcelona.cat/superilles/es

Alcalá-Santaella, F., Díaz de Orueta, F; Ginés, X., \& Lourés, Mª L. (2011). Una nueva agenda urbana para las grandes ciudades: crecimiento y competitividad. In M. Iglesias, M. Martí-Costa, M. Tomàs, \& J. Subirats (Ed.), Políticas urbanas en España. Grandes ciudades, actores y gobiernos locales (pp. 307-334). Barcelona: Icària

Ayuntamiento de Badajoz (2007). Plan General Municipal de Badajoz. Retrieved from https://www.ayłobadajoz.es/es/ayto/pgm/planos/nup

Bellet, C. (1995). Activitat immobiliària i polítiques urbanes dels anys vuitanta a les ciutats mitjanes catalanes. El cas de la ciutat de Lleida (Doctoral dissertation, Universitat de Lleida, Spain). Retrieved from https://www.tdx.cat/handle/10803/8189

Bellet, C. (2007). Los espacios residenciales de tipo privativo y la construcción de la nueva ciudad: visiones de privatopía. Scripta Nova, XI, 245 (08). Retrieved from http://www.ub.edu/geocrit/sn/sn-24508.htm

Bellet, C. (2014). La activación de solares urbanos: de práctica alternativa a objeto de programas municipales. Biblio 3W, XIX, 1058. Retrieved from http://www.ub.es/geocrit/b3w-1058.htm

Bellet, C. (2017). Proyectos y grandes operaciones urbanas. In Naturaleza, territorio y ciudad en un mundo global (pp. 1249-1265). Madrid: Universidad Autónoma de Madrid \& AGE.

Brandis, D. (2019). Grandes proyectos urbanos y desarrollos residenciales: del urbanismo de mercado a un nuevo modelo para Madrid. Ciudad y Territorio Estudios Territoriales, 198, 731747. Retrieved from

https://www.fomento.gob.es/CVP/detallepublicacion.aspx?idpub=BP1027

Boira, J. V. (1995). La rehabilitación urbana en los centros históricos valencianos. Cuadernos de Geografía, 58, 241-258. Retrieved from

https://ojs.uv.es/index.php/CGUV/article/view/14723

Borja, J. (2011). ¿Un cambio de ciclo o un cambio de época? Siete líneas para la reflexión y la acción. Urban (NSO1), 83-88. Retrieved from

http://polired.upm.es/index.php/urban/article/view/412/1760 
Brenner, N. (2004). New State Spaces: Urban Governance and the Rescaling of Statehood. Oxford: Oxford University Press

Brenner, N., Peck, J., \& Theodore, N. (2015). Urbanismo neoliberal. La ciudad y el imperio de los mercados. In Observatorio Metropolitano de Madrid (Ed.), El mercado contra la ciudad. Sobre globalización, gentrificación y políticas urbanas (pp. 211-244). Madrid: Traficantes de Sueños.

Burriel, E. (2008). La 'década prodigiosa' del urbanismo español (1997-2006). In Diez años de cambios en el Mundo, en la Geografía y en las Ciencias Sociales, 1999-2008. Actas del X Coloquio Internacional de Geocrítica. Barcelona: Universidad de Barcelona. Retrieved from http://www.ub.es/geocrit/-xcol/383.htm

Burriel, E. (2009). Los límites del planeamiento urbanístico municipal. El ejemplo valenciano. Documents d'Anàlisi Geogràfica, 54, 33-54. Retrieved from https://ddd.uab.cat/pub/dag/02121573n54/02121573n54p33.pdf_error_estat_espany ol

Burriel, E. (2014). El estallido de la burbuja inmobiliaria y sus efectos en el territorio. In J. M. Alberto \& J. L. Sánchez (Coord.), Geografía de la crisis económica en España (pp. 101-140). València: Universitat de València- Servei de Publicacions.

Calderón Calderón, B. (2004). La ciudad del todo urbanizable: estrategias del sector inmobiliario y nuevas e insostenibles formas de urbanización. Revista Ciudades, 8, 135-155. Retrieved from http://bit.ly/2g4NiOV

Calderón, B., \& García Cuesta, J. L. (2017). Legislación urbanística y planeamiento urbano en España, 1998-2015. Del despilfarro a la sostenibilidad. Scripta Nova, 21, 570. Retrieved from https://doi.org/10.1344/sn2017.21.19429

Calderón Calderón, B., \& García Cuesta, J. L. (2018). The structure of Spanish cities: a complex interweaving of continuity and change, uses and forms. Boletín de la Asociación de Geografía Española, 77, 283-314. http://dx.doi.org/10.21138/bage.2542

Capel, H. (2013a). La morfología de las ciudades. Ill Agentes urbanos y mercado inmobiliario. Barcelona: Serbal.

Capel, H. (2013b). Crisis de los modelos urbanos. Una mirada hacia el futuro. Mercator, 12(2), 7-27. https://doi.org/10.4215/RM2013.1202

Cochrane, A. (2007). Understanding Urban Policy. A critical approach. Oxford: Blackwell. 
Delgado Viñas, C. (2010). La ordenación territorial en Cantabria: normas, planes, proyectos y realidades. Cuadernos Geográficos, 47, 453-491, Retrieved from http://revistaseug.ugr.es/index.php/cuadgeo/article/view/616/704

Díaz-Orueta, F., Lourés, M. L., \& Pradel-Miquel, M. (2018). Transformando los modelos de crecimiento y cohesión: cambios en la gobernanza de Barcelona y Madrid. Eure, 44(131), 173191. Retrieved from https://www.eure.cl/index.php/eure/article/view/2295/1064

Díez Medina, C., \& Monclús, J. (2017). Visiones urbanas. De la cultura del plan al urbanismo paisajístico. Madrid: Abada editores.

Distrito Castellana Norte Madrid (n.d.). El Gran Proyecto de Madrid. Retrieved from https://distritocastellananorte.com/el-proyecto/

Escolano Utrilla, S., López Escolano, C., \& Pueyo Campos, A. (2018). Urbanismo neoliberal y fragmentación urbana: el caso de Zaragoza (España) en los primeros quince años del siglo XXI. Eure, 44(132), 185-212. Retrieved from

https://www.eure.cl/index.php/eure/article/view/2271/1086

Escudero Gómez, L.A. (2018). El fracaso del planeamiento urbanístico actual de la ciudad de Toledo: el Plan de Ordenación Municipal de 2007. Anales de Geografía de la Universidad Complutense, 38(2), 213-339. http://dx.doi.org/10.5209/AGUC. 62482

Fariña J., \& Naredo, J. M. (2010). Libro Blanco de la sostenibilidad en el planeamiento urbanístico español. Madrid: Ministerio de la Vivienda.

Fernández Durán, R (1993). La Explosión del Desorden. La metrópoli como espacio de la crisis global. Madrid: Editorial Fundamentos.

Fernández Maroto, M. (2015). El Plan General de Valladolid de 1984. En los orígenes de un nuevo modelo urbano. Ciudades, 18(1), Retrieved from https://doi.org/10.24197/ciudades. 18.2015

Fernández Salinas, V. (2005). De la protección a la legitimación social del patrimonio urbano en España. Scripta Nova, XX(539). https://doi.org/10.1344/sn2005.9.957

Ferrer, A., \& Sabaté, J. (1999). L'urbanisme municipal. In O. Nel.lo (Ed.), 20 anys d'Ajuntaments democràtics (pp. 117-160). Barcelona: Federació de Municipis de Catalunya. 
Ferrer, A. (2005). Introducción: la última deriva del urbanismo municipal. Papers. Regió Metropolitana de Barcelona, 43, 11-13. Retrieved from https://ddd.uab.cat/record/23956? ln=ca

Ferrer, A., \& Solà-Morales, M. (2005). El urbanismo municipal en España. Papers. Regió metropolitana de Barcelona, 43. Retrieved from https://ddd.uab.cat/record/29506? ln=ca

Font, A. (1995). Ciudad: mercancía o espacio colectivo. Ciudad y Territorio: Estudios Territoriales, 103, 37-41. Retrieved from https://dialnet.unirioja.es/ejemplar/17367

Font, A. (2000). La experiencia reciente de Cataluña Planeamiento urbanístico para el siglo XXI. Urban, 5, 60-82. Retrieved from http://polired.upm.es/index.php/urban/article/view/512

Gaja Díaz, F. (2008). El "tsunami urbanizador" en el litoral mediterráneo. El ciclo de hiperproducción inmobiliaria 1996-2006. Scripta Nova, XII, 270. Retrieved from http://www.ub.es/geocrit/sn/sn-270/sn-270-66.htm

Gaja Díaz, F. (2015a). Urbanismo concesional. Modernización, privatización y cambio de hegemonía en la acción urbana. Ciudades, Instituto Universitario de Urbanística, 18(1), $103-$ 126. hitps://doi.org/10.24197/ciudades.18.2015.103-126

Gaja Díaz, F. (2015b). Reparar los impactos de la burbuja constructora. Scripta Nova, XIX(517). Retrieved from http://www.ub.es/geocrit/sn/sn-517.pdf

García, S. (2005). Centros históricos ċherencia del pasado o construcción del presente. Agentes detonadores de un nuevo esquema de ciudad. Scripta Nova, IX, 194. Retrieved from http://www.ub.edu/geocrit/sn/sn-194-39.htm

García-Herrera, L. M. (2018). Mercantilización del espacio urbano bajo la lógica neoliberal: gentrificación y redefinición de los espacios públicos en España. In Naturaleza, territorio y ciudad en un mundo global (pp. 858-877). Madrid: Universidad Autónoma de Madrid \& AGE

Górgolas Martín, P. (2017). Burbujas inmobiliarias y planeamiento urbano en España: una amistad peligrosa. Cuadernos de Investigación urbanística, 111, 365. https://doi.org/10.20868/ciur.2017.111.3536

Hall, P. (1996). Ciudades del mañana. Barcelona: Icaria.

Harvey, D. (2013). Ciudades rebeldes. Del derecho de la ciudad a la revolución urbana. Madrid: Akal. 
Iglesias, M., Martí-Costa M., Tomàs, M., \& Subirats, J. (Eds.) (2014). Políticas urbanas en España. Grandes ciudades, actores y gobiernos locales. Barcelona: Icaria.

LaCol, Arquitectura cooperativa (2018). Construir en col.lectiu. Participació en arquitectura $i$ urbanisme. Barcelona: Pol.len.

Lois, R., Piñeira, M. J., \& Vives, S. (2016). El proceso urbanizador en España (1990-2014): Una interpretación desde la geografía y la teoría de los circuitos de capital. Scripta Nova, XX(539). Retrieved from http://www.ub.edu/geocrit/sn/sn-539.pdf

López de Lucio, R. (1993a). Ciudad y urbanismo a finales del siglo XX. València: Universitat de València-Servei de Publicacions.

López de Lucio, R. (1993b). El ensimismamiento en el 'Urbanismo Urbano" como respuesta a las limitaciones del planeamiento territorial. Ciudades, 1, 6166. https://doi.org/10.24197/ciudades.01.1993.61-66

López, I., \& Rodríguez, E. (2010). Fin de ciclo. Financiarización, territorio y sociedad de propietarios en la onda larga del capitalismo hispano (1959-2010). Madrid: Traficantes de sueños.

Martí-Costa, M., \& Tomàs, M. (2016). Crisis y evolución de la gobernanza urbana en España. Ciudad y territorio-Estudios Territoriales, XLVIII(188), 187-200. Retrieved from https://apps.fomento.gob.es/CVP/handlers/pdfhandler.ashx?idpub=BP1016

Méndez, R. (2014). Expansión y crisis del modelo neoliberal en Madrid. In R. Hidalgo \& M. Janoscka (Ed.), La ciudad neoliberal. Gentrificación y exclusión en Santiago de Chile, Buenos Aires, Ciudad de México y Madrid (pp. 217-232). Santiago de Chile: Pontificia Universidad Católica de Chile.

Méndez, R., Abad, L.D., \& Echaves, C. (2015). Atlas de la crisis. Impactos socioeconómicos y territorios vulnerables en España. València: Tirant Humanidades

Méndez Gutiérrez del Valle, R., \& Plaza Tabasco, J. (2016). Crisis inmobiliaria y desahucios hipotecarios en España: una perspectiva geogràfica. Boletín de la Asociación de Geógrafos Españoles, 71, 99-127. https://doi.org/10.21138/bage.2276

Méndez Gutiérrez del Valle, R. (2018). La telaraña financiera. Una Geografía de la financiarización y su crisis. Santiago de Chile: RiL editores, Instituto de Geografía de la Pontificia Universidad Católica de Chile. 
Miguel González, R. (2014). Metamorfosis urbana en Zaragoza. Biblio 3W, XIX(1083). Retrieved from http://www.ub.es/geocrit/b3w-1083.htm

Ministerio de Fomento (2013). Información estadística de las grandes áreas urbanas. Áreas urbanas + 50.000. Madrid: Ministerio de Fomento.

Ministerio de Fomento (2018). Sistema de Información Urbana. Madrid: Ministerio de Fomento; Dirección General de Arquitectura, Vivienda y Suelo. Retrieved from https://www.mitma.gob.es/portal-del-suelo-y-politicas-urbanas/sistema-de-informacionurbana/sistema-de-informacion-urbana-siu

Ministerio de Obras Públicas \& Urbanismo-MOPU (1990). 10 Años de planeamiento urbanístico en España. Madrid: Instituto del Territorio y Urbanismo.

Moya, L., \& Vinuesa, J. (1987). Barrios de promoción oficial de la Operación de Remodelación de Madrid, 1979-1986. Madrid: IVIMA.

Moya, L. (1981). El programa de acciones inmediatas de tres municipios del área metropolitana de Madrid, los PAI norte: Alcobendas, Colmenar Viejo y San Sebastián de los Reyes. Ciudad y Territorio, 4, 37-45. Retrieved from https://dialnet.unirioja.es/servlet/autor?codigo=138969

Muelas Jiménez, M., \& Parrilla Gorbea, E. (2008). Plan de Ordenación Municipal de Toledo, 2007. Urban, 13, 34-67. Retrieved from

http://oa.upm.es/21334/1/INVE_MEM_2008_144310.pdf

Naredo, J.M. (1996). La burbuja económico-financiera en la coyuntura económica reciente (1985-1995). Madrid: Siglo XXI de España.

Naredo, J. M. (2010). El modelo inmobiliario español y sus consecuencias. Boletín CF+S, 44, 13-27. Retrieved from http://habitat.aq.upm.es/boletin/n44/ajnar.html

Nel.lo, O. (2015). La ciudad en movimiento. Crisis social y respuesta ciudadana. Madrid: Díaz Pons.

Olazabal, E. (2018). Dinámicas y caracterización del proceso de urbanización en España (19872011). Las áreas urbanas articuladas por ciudades medias (Doctoral dissertation, Universitat de Lleida). Retrieved from https://www.tdx.cat/handle/10803/664412\#page=1

Paisaje Transversal (2018). Escuchar y transformar la ciudad. Urbanismo colaborativo y participación ciudadana. Madrid: Catarata. 
Ponce Herrero, G. (2018). El centro histórico de Orihuela (Alicante): de espacio patrimonial a espacio de rentas urbanas. Boletín de la Asociación de Geógrafos Españoles, 76, 183217. https://doi.org/10.21138/bage.2520

Rivas, J. L. de las, Fernández Maroto, M., Rodrigo González, E., \& Martínez Sierra, M. (2017). Recuperando el concepto urbanístico de barrio: unidades urbanas y regeneración urbana en Castilla y León. Ciudad y Territorio. Estudios Territoriales CYTET, XLIX(191), 45-62. Retrieved from https://apps.fomento.gob.es/CVP/handlers/pdfhandler.ashx?idpub=BP1019

Roch, F. (2015). Revolución neoliberal y utopía ciudadana, una batalla inaplazable. Ciudades, Instituto Universitario de Urbanística, 18(1), Retrieved from https://revistas.uva.es/index.php/ciudades/article/view/1116/961

Rodríguez, C. (2011). Intervención en cascos históricos: reactivación del casco medieval de Vitoria-Gasteiz. Jornada técnica: Regeneración urbana integral, revitalización de barrios y rehabilitación energética de edificios existentes. València: Instituto Valenciano de la Edificación, April 12-13. Retrieved from

http://www.lks.es/Portals/O/AreasActividad/urbanismo/materiales\%20divulgativos/5_Casc_H co_Vitoria_enero2009.pdf

Rodríguez López, J. (2006). Los booms inmobiliarios en España. Un análisis de tres períodos, Papeles de Economía Española, 109, 76-90. Retrieved from https: / / dialnet.unirioja.es/servlet/articulo?codigo $=2142662$

Romero, J. (2010). Construcción residencial y gobierno del territorio en España: de la burbuja especulativa a la recesión. Causas y consecuencias. Cuadernos Geográficos de la Universidad de Granada, 47, 17-46. Retrieved from

http://revistaseug.ugr.es/index.php/cuadgeo/article/view/600/688

Romero, J., Brandis, D., \& Melo, C. (2015). El giro neoliberal de las políticas para la Ciudad en España. Balance a partir de los casos de Madrid y Valencia. Boletín de la Asociación de Geógrafos Españoles, 69, 369-386. http://dx.doi.org/10.21138/bage. 1901

Romero González, J. (Coord.) (2019). Geografía del despilfarro en España. València: Ediciones Universitat de València.

Rullán, O. (2012). Urbanismo expansivo en el estado español: de la utopía a la realidad. In AA.V. Geografía y desafíos territoriales en el siglo XXI (pp. 165-209). Alicante: AGE/Universidad de Alicante. 
Rullán, O. (2016). La planificación urbana y territorial en tiempos de crisis. In J. Olcina \& A. Rico (Coord.), Libro jubilar en homenaje al profesor Antonio Gil Oncina (pp. 1267-1286). Alicante: Publicaciones de la Universidad de Alicante.

Sainz Gutiérrez, V. (2006). El proyecto urbano en España. Génesis y desarrollo de un urbanismo de los arquitectos. Sevilla: Publicaciones de la Universidad de Sevilla.

Schulz-Dornburg, J. (2012). Ruinas modernas. Una topografía del lucro. Barcelona: Àmbit.

Senabre, D. (2003). Desarrollo urbano y urbanística del municipio de Salamanca en el siglo XX. Scripta Nova, VII, 146(139). Retrieved from http://www.ub.es/geocrit/sn/sn-146(139).htm

Sennet, R. (2018). Building and Dwelling. Ethics for the City. New York: Farrar, Straus and Giroux. Solà Morales, M., \& Parcerisa, J. (1987). El urbanismo urbano. Forma urbana y planeamiento urbanístico en siete capitales españolas. Estudios Territoriales, 24, 33-51. Retrieved from https://dialnet.unirioja.es/servlet/articulo?codigo=81659

Somoza Medina, J. (2013). Gobernanza urbana, competitividad y procesos de renovación en las ciudades medias españolas. Boletín de la Asociación de Geógrafos Españoles, 61, 4766. http://dx.doi.org/10.21138/bage. 1535

Subirats, J. (2016). El poder de lo próximo. Las virtudes del municipalismo. Madrid: Los Libros de la Catarata.

Swyngedouw, E. (2005). Governance Innovation and the Citizen: The Janus Face of Governancebeyond-the-state. Urban Studies, 42(11), 1991-2006.

https://doi.org/10.1080/00420980500279869

Swyngedouw, E. (2018). The perverse lure of autocratic democracy, South Atlantic Quarterly, 112(2), 267-286. doi:10.1215/00382876-7381134

Swyngedouw, E. (2019). The Perverse Lure of Autocratic Postdemocracy. South Atlantic Quarterly, 112(2), 267-286. http://dx.doi.org/10.1215/00382876-7381134

Tomé Fernández, S. (2007). Los Centros Históricos de las Ciudades Españoles. Ería, 72, 7588. Retrieved from https://www.unioviedo.es/reunido/index.php/RCG/article/view/1571

Zarate Martín, A. (2007). Toledo. Planeamiento y especulación en ciudades históricas. Anales de Geografía de la Universidad Complutense de Madrid, 27(2), 151-175. Retrieved from https://revistas.ucm.es/index.php/AGUC/issue/view/AGUC070 